Revista Complutense de Historia de América

ISSN: $1132-8312$

\title{
Libros en los Andes. La biblioteca robada del cura indígena Fernando Ramos Titu Atauchi (1809)
}

\author{
Agnes Gehbald ${ }^{1}$; Carlos Zegarra Moretti ${ }^{2}$
}

Recibido: 30 de marzo de 2020 / Aceptado: 29 de noviembre de 2020

Resumen. La biblioteca del cura indígena Fernando Ramos Titu Atauchi revela una historia de los libros como objetos en los Andes rurales en el Virreinato del Perú, un espacio que habitualmente no era asociado con la lectura. En la primera década del siglo XIX, la colección de libros del doctrinero sufrió una drástica disminución en la doctrina altoandina, un área alejada de los circuitos más activos de comercio libresco en la época. Enfocándose en el estudio de la biblioteca, el artículo discute la noción del libro a fines del periodo virreinal, incluyendo temas como las vías de alfabetización, la posesión de libros por indígenas y los mecanismos de adquisición de estos bienes en el altiplano peruano. Seguidamente, el estudio se centra en la colección recopilada en Umachiri (Puno, Perú) por el eclesiástico indígena, resaltando la extensión y, sobre todo, la temática religiosa de los títulos reunidos, en donde sobresale el Ritual formulario (1631) de Juan Pérez Bocanegra, manual catequético publicado en quechua cusqueño. Por último, considerando el entorno cercano del cura Fernando, el artículo ofrece una explicación para la disminución de la colección, prestando atención al valor simbólico y económico de los libros. Con todo ello se plantea una nueva interpretación del significado de la cultura de la impresión en las comunidades indígenas a finales de la época colonial.

Palabras clave: Bibliotecas virreinales; alfabetización; cura de indios; literatura sermonaria; Cusco; Umachiri-Puno; siglo XIX.

\section{[en] Books in the Andes: The Stolen Library of the Indigenous Priest Fernando Ramos Titu Atauchi (1809)}

\begin{abstract}
The library of the indigenous priest Fernando Ramos Titu Atauchi reveals a history of books as objects in the rural Andes of the Viceroyalty of Perú, an area not usually associated with reading. In the first decade of the $19^{\text {th }}$ century, the doctrinaire's book collection suffered a drastic reduction in the High-Andean doctrine, an area far from the more active circles of the book commerce of the period. Focusing on the study of the library, the article discusses the notion of books at the end of the viceregal period and includes themes such as the pathways to literacy, the possession of books by Indians and the mechanisms for acquiring these goods in the Peruvian highlands. The study then focuses on the collection recompiled by the indigenous clergyman in Umachiri (Puno, Perú), highlighting the size and, above all, the religious theme of the titles collected, among which the Ritual Formulario (1631) of Juan Pérez Bocanegra, a manual for catechism published in Quechua from Cuzco, stands out. Finally, taking into consideration the immediate environment of Priest Fernando, the article offers an explanation for the reduction of the collection, paying attention to the symbolic and economic value of the books. All things considered, a new interpretation of the significance of the culture of printing in the indigenous communities at the end of the colonial period is proposed.
\end{abstract}

\footnotetext{
1 Universität zu Köln [Alemania]

E-mail: agnes.gehbald@hist.unibe.ch

2 Universität Bonn [Alemania]

E-mail: carlos.zegarra.moretti@gmail.com
} 
Keywords: Viceregal Libraries; Literacy; Indian Priest; Sermon Literature; Cuzco; Umachiri-Puno; 19th Century.

Sumario. 1. Lectores indígenas en espacios rurales: alfabetización. 2. Los libros del cura: composición de la biblioteca. 3. Los libros leídos del cura. 4. Los libros perdidos del cura: sustracción y robo. 5. Conclusiones. 6. Referencias bibliográficas. 7. Anexo documental.

Cómo citar: Gehbald, A.; Zegarra Moretti, C. (2021) Libros en los Andes. La biblioteca robada del cura indígena Fernando Ramos Titu Atauchi (1809), en Revista Complutense de Historia de América, 47, 181-207.

\section{Lectores indígenas en espacios rurales: alfabetización}

Una cantidad nada despreciable de libros, 157, fueron incluidos entre los bienes pertenecientes al cura de una doctrina rural andina en $1807^{3}$. Un par de años después, el número de esta colección se redujo fuertemente. En 1809, tras la muerte del doctrinero fueron inventariados solamente 60 títulos $^{4}$. El propietario de la biblioteca era Fernando Ramos Titu Atauchi, miembro de una de las familias de la "nación índica" de mayor abolengo noble del Cusco, y cura propio de Umachiri, una parroquia de indios de habla quechua ubicada en la región del Collao, en el altiplano peruano (partido de Lampa, intendencia de Puno). En él, un personaje poco estudiado empero fascinante, confluyen tres caminos singulares, que originan una combinación poco antes vista: indígena noble, cura de indios y dueño de una colección de libros que disminuyó considerablemente al final de su vida. Detrás de esta reducción se esconde la historia de un expolio, que ofrece una mirada particular a los itinerarios de estos bienes, que circularon como objetos entre distintos sitios y manos en el territorio altoandino durante el Virreinato tardío 5 .

De la misma manera y basándose en la historia de la composición y la disolución de la biblioteca del cura indígena, el presente artículo invita a reconsiderar la noción de lectores y lecturas indígenas en el virreinato peruano proponiendo que el acceso a la cultura letrada debe considerar más variables que la posesión por autoridades tradicionales indígenas y motivaciones legales. El caso de la biblioteca del cura indígena evidencia que la cultura libresca, después de 250 años tras su llegada con los españoles, logró expandirse geográficamente a espacios tan alejados de centros tipográficos como las punas puneñas y que, sobre todo, alcanzó a otros grupos indígenas - de los hasta ahora estudiados- con sus propios intereses librescos. Para comprender la presencia y significado de los libros entre los nativos en los Andes rurales consideramos tres aspectos. Primero, la apropiación de la cultura libresca entre las poblaciones indígenas a fines del periodo virreinal, centrándose en el perfil

3 Autos seguidos por el procurador general de naturales don José Agustín Guamantupa, a nombre de don José Ramos Obando Tituatauchi, contra don Buenaventura Cornejo, vecino del pueblo de Umachiri. Cusco, 11-XII1810. Archivo Regional de Cusco [Perú] (en adelante ARC), Real Audiencia, Leg. 69, Exp. 25, f. 2 v.

4 Autos ejecutivos seguidos por el defensor general contra la estancia de Totorani, casa y tierras en la parroquia de Santa Ana y demás bienes del doctor don Fernando Ramos Titoatauchi, cura de la doctrina de Humachiri. Cusco, 30-IX-1808. ARC, Cabildo, Leg. 76, Exp. 1889, ff. 13r-14r.

5 Si bien, desde una postura conceptual canónica, "doctrina" y "parroquia" designan a instituciones diferentes, utilizamos como sinónimos de doctrina: parroquia de indios, parroquia de indígenas y similares. 
de los poseedores de libros y las múltiples vías de alfabetización. Segundo, conocer la biblioteca del cura Fernando Ramos, resaltando los mecanismos de adquisición de libros en ambientes rurales, la extensión de la biblioteca, y la especial temática de los títulos compilados, orientados al uso pastoral de los mismos, representado especialmente en el ejemplar del Ritual formulario de Juan Pérez Bocanegra. Por último, el artículo propone, de manera particular, los posibles valores adicionales que se pudieron otorgar a los libros por su círculo cercano.

La posesión de libros y el uso de la cultura libresca por indígenas peruanos durante el virreinato, es, a pesar de su relevancia en los estudios de intelectualidad, un tema poco estudiado a profundidad ${ }^{6}$. La historia del libro en el territorio indígena virreinal se centra en un ámbito iletrado, donde las lenguas habladas (mayoritaria, pero no únicamente, quechua y aimara) son distintas al idioma escrito (español). Es por ello por lo que el libro en el universo colonial ocupa un lugar particular y diferente al del origen ${ }^{7}$. Lo anterior queda patentado en la biblioteca estudiada, donde la mayoría de los títulos fueron escritos en español y procedieron de talleres de imprenta españoles. Su dueño pertenecía a una de las familias indígenas de mayor linaje del Cusco urbano en la segunda mitad del siglo XVIII, cuya nobleza hundiría sus raíces en la descendencia del inca Huayna Cápac. Don Fernando era hijo de doña María Vásquez Obando, descendiente de una familia de caciques del barrio de Santa Ana, y de Asencio Ramos Titu Atauchi, curaca y "capitán de indios nobles y principales de las ocho parroquias" cusqueñas. Esta pareja concibió una fructífera prole. De entre sus siete hermanos, Fernando -que aparenta ser el primer hijo varón de la progenie- resalta por haber tomado la carrera eclesiástica secular, poseer una educación superior y tener un gusto por los libros?.

Así como sucedió con don Fernando, los sacerdotes y su literacidad jugaron un rol relevante en la intermediación en las regiones rurales. Debido a la distinción entre habitantes, actividades económicas, costumbres e infraestructura entre las ciudades y las zonas periféricas del Perú, la historiografía separó, inicialmente, en dos las esferas de la literacidad. Esa escisión espacial subrayaba una predominancia de lo colonial, español y escrito, por un lado, y lo indígena, quechua y oral, por otro. La bipartición teórica del espacio generó la siguiente imagen: en las ciudades residió un grupo social especializado - los dueños de la escritura en una sociedad analfabeta- que ejerció la administración colonial y la evangelización desde la fortaleza de "la ciudad letrada"10. No obstante, ese binomio estático ha sido corregido al quedar demostrado que los indígenas alteraron el sistema de la literacidad cuando lo requerían. Ello queda plasmado en la vida en los pueblos andinos, por medio de, particularmente, dos campos: lo jurídico y lo doctrinal y, a través de agentes, díganse los

\footnotetext{
Un resumen historiográfico es presentado por Guibovich Pérez, 2017.

Para la peculiaridad de la cultura impresa en contextos coloniales, véase Ballantyne, 2007.

Sobre la familia de los Ramos Titu Atauchi se disponen de varias referencias bibliográficas, pero puntuales. Quizá fue Temple la primera en incluir a este linaje en la historiografía. Temple, 1949: 56-57. De Fernando, en específico, se ha resaltado ser cura indígena y su labor en el bando realista en la rebelión de Túpac Amaru. O'Phelan Godoy, 1995: 63; Walker, 2015: 161.

9 Los hijos de María y Asencio eran, según el orden establecido en el testamento de sus padres, los siguientes: Tomasa, Bernarda, Martina, María, Ana, Teresa, Fernando y José. Hemos establecido el número de ocho hijos considerando el testimonio de Mateo Pumacahua en una declaración judicial. De los autos seguidos sobre la testamentaria del doctor don Fernando Ramos Tituatauchi. Cusco, 12-VI-1809. Empero existe, entre los investigadores, una falta de consenso en el número exacto de las hermanas.

10 Así el concepto influyente de Ángel Rama, publicado por primera vez en 1984. Rama, 2004.
} 
escribanos del pueblo, los protectores de indios y los curas - casi en su totalidad de origen español. De esta manera, el acceso a lo escrito se ampliaba a aquellos que no sabían leer ${ }^{11}$. Aparte de intermediarios de origen peninsular o criollo, se encuentran los letrados indígenas, como era don Fernando ${ }^{12}$.

La formulación, intercambio y lectura por los letrados indígenas se produjo, en el Perú, casi exclusivamente en español y no en lenguas nativas como ocurrió en la zona mesoamericana ${ }^{13}$. Su capacidad de leer y escribir los empoderó con una movilidad social y los hizo "intelectuales indígenas" produciendo, de esta manera, conocimientos, y defendiendo los derechos de sus pueblos dentro de las estructuras coloniales ${ }^{14}$. Los textos que compusieron o emplearon transformaron la vida social, legal y administrativa. Testamentos, convenios, ventas, cartas, testimonios, expedientes, partidas sacramentales y otros papeles manuscritos junto con textos impresos como cédulas, títulos y otros más, ocuparon un sitio decisivo, aunque particular en el mundo rural. Más excepcional aún era la presencia en manos privadas de libros de variados títulos, impresos y encuadernados, que podían estar conformados, en algunos casos, de varios tomos. Si bien las grandes ciudades congregaron el mayor comercio de libros, las arterias del tránsito libresco también alcanzaron territorios indígenas en contornos rurales, quedando reflejado en la biblioteca de don Fernando en Umachiri.

¿Quiénes fueron los poseedores de libros en el ámbito rural-indígena? En un artículo sobre "indios y libros", Pedro Guibovich esboza - no sin antes advertir la escasez de estudios sistemáticos sobre el tema- dos ideas: primera, que los principales lectores indígenas fueron caciques y, segunda, que hubo un interés recurrente en la lectura jurídica con el fin de sustentar causas judiciales ante el poder virreinal. La figura del curaca tacneño Santiago Ara representa la tesis de Guibovich: estudió derecho en Chuquisaca, se graduó de doctor y, acorde a su profesión de abogado de la Real Audiencia de Charcas, poseyó literatura legal entre los 59 títulos de su biblioteca inventariada en $1792^{15}$. Si bien no abundan las menciones en los archivos sobre poseedores indígenas de libros, referencias bibliográficas -aunque muy cortasprueban su presencia en áreas andinas y por parte de señores étnicos en los siglos

11 Partiendo del concepto teórico de Ángel Rama. Adorno, 1987. Para una renovación del concepto en el contexto histórico novohispano, afirmando la exclusión de todo indígena de "la ciudad letrada", véase Chocano Mena, 2000. Aplicando el concepto a la realidad cusqueña, Kathryn Burns ha mostrado que "la ciudad letrada" era menos exclusiva que lo mantenido por Rama por la actividad de escribanos quienes manejaban las fórmulas legales y escribían como manos ajenas, facilitando una escritura delegada y la participación por varios sujetos. Burns, 2010. Sobre la participación de escritores indígenas y mestizos en los Andes quienes reivindicaron justicia para el sistema colonial, Alcira Dueñas ha presentado casos del mundo andino. Dueñas, 2010. Compárese, además, la variedad de casos presentados en Rappaport - Cummins, 2012.

12 Sobre los curas indios disponemos de algunas ideas del posible significado que su aparición tuvo para las élites indígenas en tiempos tardío-virreinales, proponiéndose que la opción eclesiástica fue una nueva vía emprendida por estas familias para seguir manteniendo su autoridad en la sociedad virreinal a través de nuevos mecanismos de validación. O’Phelan Godoy, 2002. También, Garrett, 2002 y Zegarra Moretti 2020a. Sobre posibles conflictos entre caciques y curas, véase Cahill, 1984: 268-269. Para el caso de Nueva España, los estudios de esta temática han recibido importantes aportes recientes gracias a Menegus (2009) y Menegus - Aguirre (2006: 2233 y 195-221), quienes sugirieren que el ingreso de nativos fue facilitado por contactos directos con personajes del alto clero llegando a ocupar, salvo significativas excepciones, puestos en el bajo clero. Aparte del caso de don Fernando aquí estudiado, en ningún otro se ha mencionado la posesión de libros por estos personajes.

13 Referente a la producción "mundana” en lenguas nativas en Perú, véase una revisión en Durston, 2008.

14 Para el concepto de "indígenas intelectuales”, véase Ramos - Yannakakis, 2014: 7.

15 Guibovich Pérez, 2017: 184-186 y 188-189; 1990b. 
XVIII y XIX ${ }^{16}$. Por ejemplo, en su estudio sobre los "yngas nobles" del Cusco entre 1750 y 1825 , David Garrett informa que solo en uno de 150 testamentos indígenas detectados se encuentra mención a estos bienes ${ }^{17}$. De la circunscripción altoandina provienen más noticias como la de Gabriel Cama Condorsayna, cacique de Macarí, en el altiplano de la región de Puno, quien poseyó cuatro libros. Igualmente, la pareja Fausto Jáuregui Colque y Rafaela Tito Atauchi, curacas de Pucarani, en los Andes de La Paz, reunió una colección significativa de 50 tomos, sobre todo conformada por títulos religiosos (dígase breviarios y vidas de santos) e, incluso, un texto en idioma aimara ${ }^{18}$. A este álbum de indígenas poseedores de libros en la etapa borbónica se puede agregar el siguiente registro inédito: Esteban Condorpusa y Gamarra, coronel, gobernador y cacique principal del pueblo de San Juan Bautista de la Chimba, cerca de Arequipa, poseyó en 1785 una biblioteca compuesta por 32 libros $^{19}$. Entre ellos se encuentran textos jurídicos (Leyes de Indias y Ordenanzas del Perú), históricos (Historia de la Florida) y religiosos (Flos sanctorum y otras Vidas de Santos) ${ }^{20}$. De lo anterior resalta que, efectivamente, muchos de los propietarios conocidos de obras, tanto en zonas urbanas como rurales, eran miembros de familias cacicales y pertenecían a autoridades del gobierno civil de la República de Indios.

A pesar de estas menciones es muy poco lo que se sabe sobre la cultura libresca de los indígenas. Sin embargo, nuevos hallazgos documentales pueden matizar y ampliar esta mirada. Si bien el caso del cura Fernando es ilustrativo de indígenas no caciques -aunque sí integrante de la élite indígena- poseedores de libros no jurídicos, no fue el único. En el pueblo de Santiago del Cercado, en Lima, don Fernando Chapilliquén Nonura conservó en sus últimos días una obra muy conocida. Entre las posesiones de Chapilliquén, quien era oriundo de Sechura, en Piura, y que llegó a ser nombrado capitán de una de las milicias de Lima ${ }^{21}$, se listó, en 1773, un libro no relacionado con su oficio castrense, pero sí con su etnia indígena, el cual era "un tomo de a folio de los Comentarios de este Reyno su autor el Ynga Garcilaso"22. Este autor fue popular, sabiendo que incluso, en 1777, el rebelde José Gabriel Túpac Amaru llevó "1 obra de Garcilaso", tras su estadía en Lima, a la ciudad de Tungasuca ${ }^{23}$. Después de la rebelión tupacamarista, los Comentarios Reales, obra que se dedica a explicar el origen de los Incas, fueron prohibidos en $1782^{24}$. Si bien, treinta años

16 En lo que sigue se citan varias referencias a indígenas poseedores de libros que se conocen para la época. Otros ejemplos para el siglo XVII en Alaperrine-Bouyer, 2007: 210; Guibovich Pérez, 2017: 184-185; Monsalve Zanatti, 2003: 161-162.

17 Garrett, 2005: 173.

18 Ibidem: 173-174.

19 Un antepasado suyo, don Juan Condorpusa, cacique del mismo poblado en 1664, poseyó para uso legal un ejemplar de la Política Indiana de Juan de Solórzano. Puente Luna - Honores, 2016: 26. Esta indicación es relevante en cuanto abre la posibilidad de la posesión y, posiblemente, transmisión de libros entre generaciones.

20 Cobdicilio de don Esteban Condorpusa. Arequipa, 2-IV-1785. Archivo Regional de Arequipa [Perú], Escribano Manuel Gonzales de la Fuente, Prot. 334, Año 1785, ff. 310, 421.

21 Testamento de don Fernando Chapilliquen Nonura Yndio Capitan. Lima, 14-I-1773. Archivo General de la Nación [Perú] (en adelante AGN), Escribano Francisco Luque, Prot. 624, Año 1773, f. 13v.

22 Inventario de bienes de Fernando Nonura. Lima, 28-I-1773. AGN, Escribano Marcos Velásquez, Prot. 1185, Año 1773, ff. 910-911. El inventario se realizó por el peligro de fuga de quien poseía estos bienes (Josefa Villalobos). Se intuyó ocultamiento de bienes por el tenedor de bienes nombrado por Fernando. Se incluyó, además, "varios papeles de música", que podrían no ser impresos, sino manuscritos.

23 Cuaderno de guías de efectos de la tierra internados en el Cusco. AGN, Real Aduana Cusco, 162.18, Año 1777, ff. 51-51v.. Para el contexto y un análisis de esta guía de registro aduanero, véase O’Phelan, 2013: 45-46.

24 Torre Revello, 1940: 73 y CLXXXIX-CXC; Guibovich Pérez, 1990a. 
después, la biblioteca del cura Fernando en Umachiri -superior cuantitativamente a la de Chapilliquén- no acogió este título famoso sobre el pasado prehispánico, sí incluyó, como detallaremos más adelante, uno con relación al adoctrinamiento en lengua quechua.

Las evidencias descritas son, no obstante, reflejo de que fue una minoría indígena la que en el Perú rural atesoró libros, lo cual se compagina, asimismo, con el porcentaje menor de los que supieron leer. Es sustancial repensar la relación mutua, pero por nada interdependiente, entre, por una parte, acceso y posesión de libros y, por otra parte, literacidad y lectura. En muchos casos coincidió la posesión de libros con literacidad, abriendo su contenido al dueño. Sin embargo, la posesión y el consumo no tenían que coincidir. El inventario de libros del cura Fernando no comprende descripciones sobre el estado material del objeto -como en otros casos parecidos, sobre todo para la tasación de libros- que podrían ofrecer pistas sobre el uso a través del desgaste. Como objetos, los libros contenían otros valores adicionales aparte del valor económico, tales como, por ejemplo, medio educativo o prestigio social. La habilidad de leer no era un requisito inevitable para la tenencia de $\operatorname{libros}^{25}$. De la misma manera, literacidad no correspondía con tener libros. En Umachiri, Fernando pertenecía a un grupo reducido de indígenas que cosecharon el hábito de la lectura y quizá más reducido de los que, además, poseían libros. Otra alusión a la literacidad en Umachiri es cuando el párroco estudiado nombró, en 1788, amanuense para los libros parroquiales a un posible indígena: Gregorio Ynquilltupa Balladares y Tude$\mathrm{la}^{26}$. Se puede agregar al círculo de literacidad al indígena Simeón Corimanya, cantor de la doctrina y amigo íntimo de Fernando Ramos ${ }^{27}$. En un contexto de educación indígena limitada, estas referencias nos conducen a repensar en las vías de formación que les permitió aprender a leer.

En general, la alfabetización en el Virreinato siguió una clara estratificación vertical con la mayoría de las instituciones dirigidas a españoles peninsulares, criollos y mestizos. Para los indígenas existieron diferentes vías de instrucción: escuelas públicas, colegios e instituciones exclusivas para la élite, y, finalmente, clases particulares. En pocos pueblos del virreinato peruano funcionaron escuelas para la alfabetización indígena. De acuerdo con las reformas borbónicas de la época, se emprendieron varios intentos de establecer escuelas públicas en cada pueblo de indios o parroquia como en 1772,1800 y $1820^{28}$. Aunque tanto la Corona como la Iglesia fueron promotores de la educación de primeras letras, esta política educativa se dificultó por la escasez de maestros, la dispersión de alumnos en las zonas rurales y los

25 Referente a cuestiones metodológicas en torno al análisis de inventarios de libros, prestando atención a las diferencias entre una lista de libros, la posesión de libros y la lectura, véase; Rial, 2010: 75-79; Walsby, 2013. Sobre características de bibliotecas particulares del siglo XVIII, demostrado de manera microanalítica por inventarios de bienes de dos prelados novohispanos, Coudart - Gómez Álvarez, 2003. Adicional al valor económico, el énfasis en la historia material de objetos destaca el valor del libro como símbolo, mirase, por ejemplo, Cummings, 2010 .

26 Libro de Bautizos de la parroquia de Umachiri (1801-1809). Archivo Histórico de la Prelatura de Ayaviri [Perú] (en adelante APA), Libros Parroquiales, Umachiri, Años 1801-1809, Libro de Bautizos 2. A pesar de que tal apellido se puede vincular a las élites indígenas del Cusco urbano, no sabemos más de este sujeto. Indígenas nobles del cercado de Cusco con apellido Inquiltupa, en Amado Gonzales, 2017: 221-222.

27 De los autos seguidos sobre la testamentaria del doctor don Fernando Ramos Tituatauchi. Cusco, 12-VI-1809. ARC, Real Audiencia, Leg. 66, Exp. 7, ff. 69v-71r.

28 Sobre la educación escolar para indígenas, Macera, 1966: 331; Mannheim, 1991: 75; Ramírez, 2008; Soule, 2014: 97. 
altos $\operatorname{costos}^{29}$. En la región de Cusco, según lo que se conoce hasta ahora, estuvieron disponibles solamente dos escuelas públicas rurales al final del siglo XVIII: en Aymaraes y Calca. Las autoridades locales coincidieron que las tasas de enseñanza exigida por los maestros y el material requerido no podían ser cubiertas por los fondos de comunidad ${ }^{30}$. A pesar de tales obstáculos en el camino de la alfabetización para familias indígenas, a la élite se le presentaba menos dificultoso. Incluía entre sus privilegios reales el acceso a la enseñanza, negado para el "indio del común". La ciudad de Cusco, lugar de origen de la familia Titu Atauchi, disponía de espacios especiales de educación, siendo el colegio San Francisco de Borja el más representativo -mas no el único- para la formación de hijos varones nobles ${ }^{31}$.

Aparte de esa vía institucional, se debe tomar en cuenta otras alternativas de instrucción no formal. En ese sentido, las casas de recogimiento permitieron la educación de varones indígenas ${ }^{32}$. Algunas de las hijas de indígenas, por su parte, recibieron una enseñanza en castellano en los beaterios donde aprendieron a leer y escribir, cantar y tocar instrumentos ${ }^{33}$. El método por clases particulares fue otro camino no formal para la instrucción en los Andes, que permitió compensar la falta de acceso a instituciones educativas. Esta instrucción, llevada a cabo generalmente en edad pueril, benefició por igual a indígenas y no-indígenas. Fue financiada a través del trabajo del estudiante, a veces con una pensión adicional, pagada no necesariamente por los progenitores, y siguió un plan educativo formado a requerimiento del estudiante. Se puede anotar que esta vía estuvo a cargo de docentes privados, siendo algunos de ellos religiosos ${ }^{34}$. Tal es el caso de Fr. Isidro de Echevarría, padre lector mercedario de Cusco, quien instruyó a un supuesto sobrino de don José Zegarra en materias filosóficas por cuatro años hacia $1787^{35}$. Preceptores laicos a cargo de un mayor número de discípulos fue otra forma de enseñanza experimentada en el Cusco, siendo este el caso del maestro de latinidad don Ildefonso Fernández de Luna en $1790^{36}$. Asimismo, existió la posibilidad de formación técnica artística y utilitaria. En ese sentido, el párroco de Catca, Pedro Miranda, encargó al organista Gabriel José Altamirano la formación musical del joven Juan Yucra en su doctrina indígena. Altamirano tenía un plazo máximo de doce meses "para que le enseñe a tocar el órgano y juntamente a cantar por solfa". Transcurrido el periodo de enseñanza, el aprendiz debía ser ducho en órgano y canto de tal manera "que pueda asistir en cualquier coro, a oficiar cualquier oficio divino como son misas vísperas y otros oficios que se ofrecen en la Iglesia asistiendo en su casa de día y de noche sin hacer falta, ni fallas". Por tal servicio educativo, pactado el 31 de mayo de

\footnotetext{
Vargas Ugarte, 1972.

Macera, 1966: 335 y 346-348.

Alaperrine-Bouyer, 2007; Charles, 2014. También, Escobari de Quejazu, 2009.

Ramos, 2014.

Burns, 2002.

34 No se sabe mucho sobre los contratos de aprendizaje, aunque esa vía de instrucción gremial sustituyó de manera significativa la ausente educación del Estado durante la época colonial, según la descripción de Macera, 1966: 351. Sobre las particularidades de estudiar esas fuentes documentales, véase Guibovich Pérez, 1993: 272. Para una descripción del diverso panorama educativo para indígenas en Potosí de inicios del siglo XVII, véase Inch, 2010: 510-518.

35 Autos seguidos por el fraile Isidro de Echevarría, religioso de la orden de la Merced, contra don José Zegarra, por el cobro de 80 pesos anuales por la enseñanza en teología y los alimentos de su sobrino Hermenegildo Zegarra. Cusco, 1787. ARC, Cabildo, Leg. 59, Exp. 1430.

36 Autos seguidos por don Ildefonso Luna, maestro de latinidad contra el procurador de causas don Manuel Sánchez Ysla, por los insultos y malos tratos hechos a los niños de su aula. Cusco, 13-XI-1790. ARC, Real Audiencia, Leg. 104, Exp. 5.
} 
1749, el eclesiástico bienhechor se comprometió a pagar 60 pesos al maestro, desembolsando la mitad por adelantado y el saldo al finalizar la instrucción ${ }^{37}$. En este caso no se precisa si el novel Juan ya era letrado o si la alfabetización formaba parte del programa de enseñanza, pero es probable que la facilidad de leer le ayudase a aprender a tocar el órgano y a cantar. Una vez instruido, quienes habían aprendido a leer, podían enseñarlo a sus familiares, hijos o nietos, replicando el efecto educativo ${ }^{38}$.

Concerniente a la educación que lograron los ochos hijos de la familia Ramos Titu Atauchi, el nivel formativo alcanzado entre ellos es dispar. No ha sido posible encontrar la matrícula de los hijos Fernando y José al mentado colegio San Borja, lo que puede deberse a que no ha perdurado el registro o no asistieron. Aunque, como se aclaró, éste no fue el único núcleo de enseñanza. En el testamento de su madre, signado en 1749 , se testimonió que el futuro presbítero Fernando era entonces colegial de San Antonio ${ }^{39}$. Esta indicación permite incluir al seminario antoniano como otro centro educativo para la élite indígena masculina cusqueña a mediados del siglo XVIII. Vale hacer dos precisiones que diferencian a San Antonio de San Borja: no se restringía a la juventud noble, sino que entre su alumnado podían encontrarse estudiantes de menor condición social; y que San Antonio tenía una clara orientación hacia la carrera eclesiástica, impartiendo una educación superior ${ }^{40}$. En cuanto al hermano José, heredero del puesto cacical, mostró ser ladino y buen conocedor de los mecanismos de justicia y economía virreinales. En varias ocasiones, él fue el defensor del patrimonio de sus familiares -sobre todo de la herencia de su eclesiástico hermano- compareciendo ante la Audiencia de Cusco y otros tribunales menores ${ }^{41}$.

Como en la sociedad de la época, el género afectó a la literacidad de sus miembros y la familia de los Tito Atauchi no fue la excepción. A diferencia de la formación básica e, incluso, superior que alcanzaron los varones, de las hijas no ha llegado testimonios de su literacidad. Si bien se sabe poco sobre la alfabetización de las seis hermanas de Fernando, se han encontrado alusiones a que Tomasa y Martina eran iletradas al declarar no saber firmar ${ }^{42}$. Otras mujeres indígenas lograron obtener una formación significativa, por ejemplo, en los ya mencionados conventos y beaterios, posibles lugares donde aprender a leer, escribir y hacer música (la crítica de representantes del sistema educativo tradicional en la capital a finales del XVIII confirma el rol de estos espacios como centros de instrucción femenina $)^{43}$. A pesar de ello, el porcentaje

37 Asiento de aprendiz, el doctor don Pedro Fernández de Miranda, con Gabriel Joseph Altamirano de Torres. Cusco, 31-V-1749. ARC, Escribano Juan Bautista Gamarra, Prot. 144 [antes Prot. 135], Año 1749. Juan Yucra era hijo legítimo de Pedro Yucra e Isabel Sisa, feligreses de la doctrina indígena dirigido por Pedro Miranda.

38 De esa práctica de enseñanza privada y familiar - difícil de documentar- se sabe por ejemplo en torno a las incursiones con pasquines en pueblos del altiplano en 1814 y 1815. Glave, 2005: 136. Igualmente se conoce, sin mucho detalle, el caso de la formación particular de los hijos de José Gabriel Túpac Amaru, quienes fueron instruidos por el maestro Diego Ortigoza, criollo natural de Arequipa de 52 años. O’Phelan, 2013: 80.

39 Testamento de doña María Vásquez Obando, Cusco, I-1749. ARC, Escribano Juan Bautista Gamarra, Prot. 142 [antes Prot. 133], Año 1749.

40 Valcárcel, 1968: 85-86. Mientras que no se sabe más sobre los materiales de enseñanza en San Antonio, la biblioteca de San Borja comprendía 257 tomos en el momento de la expulsión de los jesuitas como ha estudiado Alaperrine-Bouyer, 2005: 168.

41 Zegarra Moretti, 2020a.

42 Testamento de doña Tomasa Titu Atauchi, Cusco, 23-VIII-1758. ARC, Escribano Juan Bautista Gamarra, Prot. 142 [antes Prot. 133], Año 1758; Autos seguidos por don José Ramos Tito Atauchi Obando, cacique de la parroquia de Santa Ana, albacea de los bienes que quedaron por fin y muerte de doña Martina Ramos Tito Atauchi, su hermana. Cusco, 30-V-1783. ARC, Corregimiento, Leg. 63, Exp. 1424, f. 9v.

43 Burns, 2002: 126-127; Rosas Lauro, 2004: 137. 
de integrantes femeninas de familias cacicales que dominaron la lectura y la escritura era muy bajo. En muchas ocasiones, ellas recibían una educación oral y tradicional ${ }^{44}$. Si una indígena sabía leer no hubo razón para no poseer libros y cultivar el hábito de la lectura. Doña Martina Chiguantupa da prueba de ello. Ella era una mujer soltera natural de La Paz, cacica de Colquepata y, en 1785, se autodescribió de la siguiente manera: "estoi Instruida en ambos Idiomas Indio, y Español y saber leer y escribir, por la buena educacion y Doctrina que me dieron mis Padres" ${ }^{45}$. Según quedó registrado en el testamento que ella misma rubricó en 1801, entre sus bienes se encontraron nueve obras de oración de autores como Antonio de Molina o Pedro de Santa María y Ulloa, más la notable cantidad de cuarenta novenas de diferentes devociones ${ }^{46}$.

\section{Los libros del cura: composición de la biblioteca}

Ante este fondo de alfabetización indígena, la biblioteca de Fernando Ramos en la doctrina altoandina compuesta por 157 títulos era de considerable volumen en el momento de su primer inventario en 1807. Antes de indagar en el misterioso caso de la disminución de la biblioteca, sucedido un par de años después, interesa trazar la composición de la colección mirando los posibles caminos del comercio libresco y la temática de los títulos recopilados por don Fernando, cuyo inventario se encuentra en el anexo.

Aunque en la capital peruana se produjo un mercado próspero de libros, este dinamismo no se extendió de por sí a las regiones rurales. En la Lima colonial, los libros eran tratados como mercancías cotidianas que se podían comprar en tiendas como en los cajones ubicados en calles y esquinas. Los interesados en adquirir libros que no eran residentes limeños o de otros centros comerciales - tal fue la situación de don Fernando- necesitaban insertarse en estas redes para obtener los títulos deseados. Las guías de la Real Aduana reflejan la práctica, si bien no muy recurrente, de despachar libros -empaquetados en cajones y transportados por mulas de arrieros-a diferentes destinos de la sierra ${ }^{47}$. El sólido sistema de distribución mercantil con rutas comerciales a Cusco, a Puno, a Arequipa y al Alto Perú permitió, de esta manera, que libros puedan alcanzar lugares remotos de áreas rurales, en donde los esperaban los curas doctrineros ${ }^{48}$.

En lo referente a las posibles vías de adquisición de los libros por don Fernando, parece que la biblioteca fue el resultado de la adquisición por el mismo cura. Se puede descartar la herencia familiar de libros, ya que en el testamento de sus progenitores no se hizo mención alguna a la tenencia de ellos, aunque sí de otros objetos culturales como pinturas, las cuales fueron legadas a las hijas ${ }^{49}$. La herencia parroquial

44 Alaperrine-Bouyer, 2007: 225-232.

45 Venta de una casita con su huerta de doña Martina Chiguantupa Pumayalli a la señora doña Juliana de Andia. Cusco, 1785. ARC, Escribano Ambrosio Arias Lira, Leg. 41, Año 1785, f. 540.

46 Codicilo de doña Martina Chiguantupa de la Paz. Cusco, 7-XII.1801. ARC, Escribano Melchor Ayesta, Leg. 50, Año 1801, ff. 405-406; Garrett, 2005: 173.

47 Sobre el mercado librero en Lima y los envíos comerciales desde la capital a otras ciudades y villas en el Virreinato, consúltese Gehbald, 2020: 162-177 y 187-193.

48 Para un estudio sobre la posesión de libros por parte del clero durante el siglo XVI y XVII, véase Guibovich Pérez, 2010.

49 Testamento de doña María Vásquez Obando, Cusco, I-1749. ARC, Escribano Juan Bautista Gamarra, Prot. 142 [antes Prot. 133], Año 1749. 
queda igualmente descartada, ya que los libros se señalaron como bienes propios del cura y no de la doctrina ${ }^{50}$. En lo concerniente a la compra, se solía realizar por medio de contactos con mercaderes o de intermediarios conocidos en las ciudades, o, para el caso de libros usados y revendidos, en las almonedas locales. En la región de Puno - de menor dinamismo comercial que Cusco- deben haber circulado cierta cantidad de libros, mayoritariamente en manos de profesionales, además de los que iban a la Juli jesuita.

Contrastando la extensión de la colección de don Fernando con otras de la región, la estudiada resalta cuantitativamente. Estudiando bibliotecas comparativamente, Pablo Macera mantiene que las colecciones de sacerdotes solían contar no más de diez o veinte libros ${ }^{51}$. Comparable con la de Fernando era otra biblioteca contemporánea de un cura español, Miguel Antonio Arze, residente en la ciudad de Puno, obispado de La Paz, quien llegó a juntar, en 1813, 76 títulos, más 15 en mal estado $^{52}$. Incluso clérigos de mayor jerarquía no poseían tantos libros como el cura indígena, por ejemplo, el chantre de la diócesis de Cusco, don Joseph de Segura y Melo, natural de Lima, poseyó al momento de su muerte, en 1776, una biblioteca compuesta por 22 títulos $^{53}$. Don Marcelo de la Riva, cura español de Chinchero, en Cusco, poseyó una biblioteca, la cual -al ser inventariada en 1792-contabilizó 32 títulos ${ }^{54}$. Igualmente, en 1807, el presbítero Juan de Aragón, en el mismo obispado, computó 33 ítems de libros en su testamento ${ }^{55}$. Si bien una biblioteca conformada por más de media centuria de títulos podía considerarse relevante, otros llegaron a acumular inmensas colecciones en el ámbito andino ${ }^{56}$. Es el caso de la colección del abogado de Cusco, Josef Mariano de Lorena, la cual fue inventariada en julio de 1822 llegando a 752 impresos o del eclesiástico Ignacio de Castro con 706 en $1792^{57}$. Otro ejemplo aún más sorprendente corresponde a la biblioteca del eclesiástico Die-

50 Si bien un antecesor suyo, Francisco José de Marán, quien estuvo a cargo de la dirección espiritual de Umachiri desde fines de 1760 hasta, al menos, abril de 1767 (Francisco Joseph de Marán presenta la relación de sus méritos como opositor a la canonjía magistral de la catedral. Cusco, 4-XII-1765. Archivo Arzobispal de Cusco [Perú] (en adelante AAC), Colonia, LV, Único, 23; Libro de Entierros de Umachiri. APA, LP, Umachiri, Libro de Entierros 1), poseyó libros, sólo conocemos de la existencia de estos unos años después de su estancia altiplánica. A fines de 1799 y por motivo de ser designado obispo de La Concepción -tras lo cual será ascendido a la silla de la diócesis de Santiago de Chile- se inventarió su biblioteca en Cusco. No existe evidencia exacta de la fecha de la conformación de su colección ni si estuvo acompañado de estos libros en Umachiri dos décadas antes de la llegada de don Fernando, pero es un dato por considerar sobre todo al encontrar títulos en común entre estas dos bibliotecas: Perfeto confesor, $i$ cura de almas de Machado de Chávez y Sermones del jesuita Vieira, véase Dougnac Rodríguez, 1990: 595 y 603-604.

51 Macera, 1977: 292.

52 Testamentaria del cura Miguel Antonio Arze. Archivo Histórico de la Prelatura de Juli [Perú] (en adelante APJ), Judicial, Testamentaria del cura Miguel Antonio Arze, ff. 24v-28v. Arze fue cura propio y vicario de San Sebastián de Zepita entre, al menos, junio de 1788 y noviembre de 1793, Libro de Matrimonios de Zepita (1788). APJ, LP, San Sebastián de Zepita, Libro de Matrimonios, 1788, 1799.

53 Testamento, inventario y sucesión del doctor don Joseph de Segura, chantré dignidad. Cusco, 17-IX-1776. AAC, Colonia VII, 3, 59.

54 Autos seguidos por el doctor Simón Bobadilla, albacea testamentario, tenedor de bienes del cura de Chinchero, Marcelo de la Riva, contra Tomasa Bobadilla sobre inventario del cura. Cusco, 1792. ARC, Cabildo, Leg. 63, Cuad. 13, ff. 3v-4r.

55 Testamento del presbítero don Juan de Aragón. Cusco, 14-I-1807. ARC, Escribano Pedro Joaquín de Gamarra, Prot. 78, Año 1807, ff. 268-268v.

56 Sobre bibliotecas de cusqueños, véase Cahill, 1984: 260.

57 Autos seguidos por don Juan José Miota y doña Juana Vera, albaceas y tenedores de bienes del finado don Josef Mariano de Lorena, sobre la facción de los inventarios de bienes. Cusco, 18-VI-1822. ARC, Cabildo, Leg. 88, Cuad. 31; Villanueva Urteaga, 1974: 156. 
go Esquivel y Navia, de la cual se mencionaba en el último cuarto del siglo XVIII estar compuesta por más de un millar y que estuvo en disputa entre los conventos mercedarios y franciscanos de la ciudad de $\mathrm{Cusco}^{58}$. Incluso en comparación con otras colecciones privadas de la aristocracia colonial limeña, que no superan muchas veces los 200 volúmenes ${ }^{59}$, los 157 "libros" -la mención no distinguió entre títulos y tomos- de don Fernando significaban una cantidad respetable para el contexto peruano. Lo anterior permite sostener que la biblioteca de don Fernando destacó, también, por su cantidad. Esto señala el nivel económico del párroco indígena, quien desarrolló actividades económicas como prestamista e inversor ${ }^{60}$, ya que, como propone Carlos Alberto González, "la inversión en libros es directamente proporcional al volumen de capital, o lo que es lo mismo, los que más dinero tienen son los que compran más libros"

La biblioteca del cura indígena ofrece un objeto de estudio excepcional por hallarse en un lugar andino y estar descrita en varias fuentes a lo largo de dos años, lo que permite un análisis material y temático. La información disponible revela, asimismo, el contorno material de la colección de don Fernando: en 1807 el casi centenar y medio de libros acopiados se encontraban "contenidos en dos estantes" 2 . De forma singular, 19 libros fueron encontrados en una caja de cedro, con chapa, pero sin llave ${ }^{63}$. Podemos enriquecer estas referencias con la del ya mencionado cura Arze, cuya biblioteca se almacenaba en "un estante de Librería sostenido de una mesa larga y angosta con los libros" ${ }^{\text {". }}$. Estantes y cajas, es decir, espacios abiertos y cerrados eran, pues, los entornos donde se solían conservar estos objetos preciados en el interior de la morada.

Respecto a la procedencia geográfica de los autores en la colección del cura Fernando, la mayoría solían ser de origen europeo y, sobre todo, español. Aparte de los ibéricos se encuentran también franceses como Gaspard Juénin y Jean Croiset, o italianos como Pablo Señeri y Domenico Viva. Sólo se ha podido detectar un autor de origen americano, el padre Juan Martínez de la Parra, jesuita mexicano autor de Luz de verdades cathólicas, título muy exitoso desde la primera impresión en 1692 en México con varias reimpresiones en España ${ }^{65}$. De la filiación clerical, sobresalen claramente los autores jesuitas (11 de 49 títulos identificados, es decir, un 22\%), lo que señala la permanencia de esta orden, por medio de su producción canónica, en los rincones de los Andes en las décadas tras su expulsión y no solamente en las

58 Causa que sigue el convento de San Francisco con el de la Merced sobre la librería del señor deán difunto. Cusco, 10-V-1779. AAC, Colonia LXXII, 2, 34.

59 Para la comparación con la capital, véase los ejemplos citados por Macera, 1977: 294 y 307-312; así como el del abogado limeño García José Lasso de Vega, conformada, en Lima en 1775, por 170 títulos, transcrito por Novoa, 2016: 277-284. Para el caso de Charcas, en 1786, la biblioteca de Juan José Segovia, abogado, catedrático de teología de la Universidad de Chuquisaca y oidor honorario de la Audiencia de Charcas, poseía 460 títulos en 1,135 volúmenes, según hace referencia Thibaud, 2010: 60 .

60 Zegarra Moretti, 2020a.

61 González Sánchez, 1996: 21.

62 Autos seguidos por el procurador general de naturales don José Agustín Guamantupa, a nombre de don José Ramos Obando Tituatauchi, contra don Buenaventura Cornejo, vecino del pueblo de Umachiri. Cusco, 11-XII1810. ARC, Real Audiencia, Leg. 69, Exp. 25, f. 2v.

63 Autos ejecutivos seguidos por el defensor general contra la estancia de Totorani, casa y tierras en la parroquia de Santa Ana y demás bienes del doctor don Fernando Ramos Titoatauchi, cura de la doctrina de Humachiri. Cusco, 30-IX-1808. ARC, Cabildo, Leg. 76, Exp. 1889, ff. 13r-14r.

64 Testamentaria del cura Miguel Antonio Arze. APJ, Judicial, Testamentaria del cura Miguel Antonio Arze, f. 24v.

65 Palau cita cerca de 30 reimpresiones para la época, Palau y Dulcet, 1954-1955: 296. 
sedes episcopales ${ }^{66}$. Además de los mencionados Jean Croiset, Pablo Señeri, Domenico Viva y Juan Martínez, son famosos autores ignacianos Pedro de Calatayud y Francisco Garau, todos encontrados en Umachiri.

En cuanto al tiempo de adquisición, es posible que don Fernando haya enriquecido su colección de impresos durante el largo periodo que estuvo en la parroquia umachireña. El prolijo coleccionista de libros estuvo a cargo de la feligresía por al menos tres décadas en el paso del siglo XVIII al XIX ${ }^{67}$. Este lapso coincide tanto con la etapa de maduración del eclesiástico como de un apogeo del comercio libresco en el virreinato peruano motivado por el incremento de la oferta y del aumento general del mercado ${ }^{68}$. Durante estos años, en el Callao, y por vía marítima, desembarcaron cantidades considerables de impresos agrupados en cajones de libros importados, mayoritariamente, desde España, pero también desde otros centros europeos. Al mismo tiempo, los talleres de imprenta limeños experimentaban un alto nivel de producción no registrados desde su inicio en $1584^{69}$. Muchos de los títulos recopilados por don Fernando, sin embargo, no eran de tirada reciente, sino debieron haber circulado en el mercado libresco del virreinato desde décadas atrás. Se debe precisar que el comercio de estos productos no se limitaba al periodo seguido tras la publicación de una obra. Era posible encontrar libros de segunda mano o de ediciones tanto anteriores como reimpresiones más recientes. Las primeras ediciones de los títulos en la colección de don Fernando datan, en menor medida, del siglo XVI (aproximadamente $11 \%$ ), más significativamente del siglo XVII (alrededor de 57\%) y, con una cuota no despreciable, del siglo XVIII (circa 32\%) ${ }^{70}$. Al encontrar autores de la talla de Fray Luis de Granada y Enrique de Villalobos, quienes publicaron por primera vez sus obras en el siglo XVI, es de suponer que los títulos en la biblioteca de don Fernando eran en muchos casos reimpresiones.

Entre los autores de las obras reunidas en Umachiri, muchos pertenecían a esos bestseller con varias reimpresiones a través de los siglos. De la producción del siglo XVII, se puede notar cierto gusto por las obras de Cristóbal Lozano, exponente del Siglo de Oro español y especializado en narrativas de temática bíblica e histórica. De este autor, don Fernando poseyó los siguientes títulos: David perseguido y Los reyes nuevos de Toledo, los cuales gozaban de especial popularidad en el sector religioso peruano. Así se muestra por la presencia del primer título entre los bienes de algunos eclesiásticos: por ejemplo, el legado al prebendado Josef Antonio de la Huerta y Laredo en Trujillo en $1777^{71}$, el poseído por el cura José Navarrete del partido de Lambayeque en $1788^{72}$ y por el presbítero Mariano Miguel del Villar en Lima en $1812^{73}$. El panorama intelectual y los intereses temáticos de la colección, según lo

\footnotetext{
66 Guibovich Pérez, 2014: 24.

67 Zegarra Moretti, 2020a.

68 García Baquero, 1992: 210.

69 Medina, 1905.

70 Basado en la identificación realizada de la primera edición de 44 de los 61 títulos del inventario del año 1809.

71 Inventario de los bienes que quedaron por fin y muerte del doctor don Victorino de la Huerta y Laredo, abogado que fue de la Real Audiencia de los Reyes, que hago yo don Josef Antonio de la Huerta y Laredo, prebendado de esta Santa Iglesia Catedral, como su albacea. Trujillo, 26-IX-1777. Archivo Regional de la Libertad, Trujillo [Perú], Escribano Laurencio Vásquez, Prot. 393, Año 1777, f. 436v.

72 Testimonio de los autos de recogimiento e inventarios de los bienes que quedaron por fin y muerte de don Juan Cazos. Lambayeque, 27-VII-1787. Archivo Regional de Lambayeque [Perú], Judicial, Partido, Caja 4.

73 Descripción y tasación de bienes del doctor don Mariano Miguel de Villar y Urrunaga. Lima, 14-I-1812. AGN, Escribano Ignacio Ayllón Salazar, Prot. 17, Año 1812, f. 57v.
} 
previamente descrito, se puede extender a la producción correspondiente al siglo XVIII (Croiset, Cliquet e Isla). En cuanto a manifestantes de las ideas dieciochescas, su presencia es, en base a lo identificado, tenue. En la línea anterior, se puede incluir a Monarquía hebrea de Vicente Bacallar y Sanna (1702), tratado político escrito en el contexto del cambio dinástico en España. De mayor relevancia es el trabajo Origen, progresos y estado actual de toda literatura, por el jesuita Juan Andrés, representante de la historiografía literaria comparativa, disciplina característica de este periodo $^{74}$. Como demuestran las referencias a otros inventarios de clérigos -algunos citados arriba- la colección de don Fernando era muy típica para un cura de la época. Predomina la temática religiosa de los títulos reunidos, y, en particular, resalta la cantidad de títulos, mayoritariamente de autores españoles y de importación, muchos en reimpresión. En vez de seguir profundizando en la temática de las obras y contrastarla con la de colecciones similares, el inventario ofrece una oportunidad para evidenciar la existencia de una colección considerable en un lugar andino. Como ha quedado demostrado en un estudio sobre los libros de un obispo de Santiago a inicios del siglo XVIII ${ }^{75}$, la fuente sobre la biblioteca de don Fernando da a conocer no solamente la existencia de libros en un ámbito no relacionado historiográficamente con la cultura libresca, sino permite, además, indagar sobre su poseedor, su entorno y su relación con los libros. Así, el caso de esta biblioteca aquí analizada plantea nuevos senderos para entender la formación y los rasgos propios de la cultura libresca del clero rural americano a finales de la época virreinal.

\section{Los libros leídos del cura}

Aunque la posesión de libros no puede llevarnos a afirmar la efectiva lectura de estos, una indagación más profunda nos puede ofrecer más luces para comprender la relación de estos objetos con su propietario. Para ello, debemos tener en cuenta dos aspectos. En primer lugar, al ser formado como sacerdote, Fernando Ramos sabía leer y, además, poseía una formación superior. Segundo, debido a su rol de cura doctrinero y administrador parroquial, parte de sus tareas pastorales coincidían con el contenido de su biblioteca. Como veremos a continuación, la dominante temática religiosa de la colección del cura indígena documenta no sólo la presencia de obras impresas en Umachiri y la tenencia por su dueño, sino sugiere también su uso y lectura. Lo anterior da pie a discutir el postulado historiográfico que ha enfatizado en la posesión de textos legales por indígenas y su uso en causas legales ${ }^{76}$. El aserto sigue siendo válido; no obstante, el caso de don Fernando pone en el escenario otra vinculación de indígenas con la cultura impresa. La posesión de libros por nativos en la cambiante sociedad virreinal de la etapa borbónica se puede explicar de diferentes maneras, influyendo el rol que estos sujetos ocuparon (entre los más estudiados: autoridades étnicas, agentes legales y eclesiásticos) y la necesidad frente a estos objetos.

El fin utilitario dado a la biblioteca por don Fernando queda plasmado en el contenido fuertemente ligado a las funciones pastorales de un sacerdote de indígenas. Para la administración y reglamentación eclesiástica, por ejemplo, poseyó títulos

\footnotetext{
Guibovich Pérez, 2014: 31.

Argouse, 2015.

Guibovich Pérez, 2017: 187.
} 
como Doctrinas prácticas del jesuita Calatayud o la Curia eclesiástica por Francisco Ortiz de Salcedo sobre el derecho práctico, además de unas copias del Concilio de Trento. También acumuló títulos de teología moral como La flor del moral por el fraile agustino Josef Faustino Cliquet u Opera omnia del jesuita Viva. A la par de la administración parroquial, tuvo un fuerte interés en la oratoria, recopilando una considerable cantidad de literatura sermonaria y textos sobre retórica y adoctrinamiento $(21 \% \text { de la biblioteca })^{77}$. El particular contenido de los sermonarios demanda una sobresaliente formación del lector. Sus declamaciones desde el púlpito durante las misas regulares como festivas, dirigidas a su feligresía altamente indígena pudieron haber estado impregnadas de los mensajes de algunas de las siguientes obras: Despertador cristiano por Joseph de Barzia y Zambrana; Enigma numérico por el franciscano Iván de Mora; Ave Maria Quaresma continua por Fray Manuel Guerra y Rivera; Sermones panegiricos por el jesuita Joseph Francisco de Isla; Triunfos de la gracia por el carmelita Francisco Alberto de San Cirilo; Sermones varios por el mercedario Juan Ynterian de Ayala; Sermones de los domingos por Fray Pedro Moreno; y Primicias panegyricas por el franciscano Gerónimo Therrero, entre otras. La existencia de esos títulos bien conocidos del canon religioso de España y las distintas partes del imperio español en la colección estudiada apunta a que el material bien pudo servirle a don Fernando para el trabajo pastoral en su curato indígena.

Don Fernando no solamente tuvo interés en la forma de adoctrinamiento según lo mandaba la Iglesia vaticana o española, sino también tuvo a mano las enseñanzas de una metodología que incluía rasgos culturales locales, la cual se articulaba con la acción pastoral del momento. A lo largo de la segunda mitad del siglo XVIII se experimentó una reforma en el nombramiento del clero diocesano en el Virreinato del Perú y especialmente en los Andes ${ }^{78}$. En ese sentido, tomó mucha relevancia que los candidatos a beneficios rurales dominaran las lenguas indígenas, teniendo los postulantes nativos cierta preferencia basado en el supuesto que el origen étnico aseguraba el dominio de la lengua autóctona. El cura Fernando encaja en esta perspectiva. En 1802 expresó haber realizado su ministerio pastoral "así en el Ydioma índico como en Castellano para mejor inteligencia de mi feligresía"79. Proponemos, así, que la biblioteca de Fernando le sirvió en sus labores parroquiales, que él describió de la siguiente manera: "a saber, administrando los Santos Sacramentos instruyendo, y explicando la Doctrina Christiana Principalmente los Misterios de nuestra Santa fee Católica Predicando el Santo Evangelio" ${ }^{80}$. Dicho ello, toma relevancia un título destinado a la doctrina en quechua que fue registrado entre los libros del cura: el Ritual formulario del clérigo cusqueño Juan Pérez Bocanegra, impreso bilingüe en quechua y español de 1631. Sin conocer las reflexiones y postura de don Fernando sobre esta obra de gran utilidad considerando la mayoritaria población quechua presente en Umachiri, esta fuente ha sido utilizada como muestra del quechua cusqueño y altiplánico, y brinda mucha información del proceso de evangelización indígena

77 Este género fue muy cultivado por los ignacianos, véase Ferlan, 2019: 125. Sobre el uso eclesiástico, social y cultural de los sermonarios y el púlpito, véanse Estenssoro, 1994; Ayrolo, 2009; y la obra dirigida por Martínez de Sánchez, 2014.

78 O'Phelan Godoy, 2002; Lavallé, 2011.

79 Expediente que acredita el pago verificado al Dr. Dn. Fernando Ramos Cura de la Doctrina de Umachiri en el Partido de Lampa por sus sínodos. Umachiri, 12-V-1802. AGN, Asuntos Eclesiásticos, Leg. 73, Exp. 138, f. 1r.

80 Expediente que acredita el pago verificado al Dr. Dn. Fernando Ramos Cura de la Doctrina de Umachiri en el Partido de Lampa por sus sínodos. Umachiri, 12-V-1802. AGN, Asuntos Eclesiásticos, Leg. 73, Exp. 138, f. 1r. 
de inicios del siglo XVII ${ }^{81}$. Bocanegra, así como el cabildo catedralicio cusqueño, se mostró en tensión contra la expansión e injerencia de los jesuitas. Esta postura se reflejó en la obra a través del proceso de traducción al español y la inclusión de sugerencias doctrinales. A diferencia de lo recomendado por el III Concilio Limense -que contó con la dominante presencia de los ignacianos- en la obra se defendía la práctica evangélica de "formular la doctrina cristiana a través de imágenes religiosas nativas" $" 82$.

En el periodo virreinal, el Ritual formulario entró a imprenta una única vez, en 1631, y sucedió en Lima por Gerónimo de Contreras ${ }^{83}$. Por la gran diferencia de tiempo entre la impresión y la propiedad por don Fernando, queda claro que debió haber adquirido este ejemplar de segunda mano. Muestra, adicionalmente, la vigencia catequética -sea excepcional o extendida- de este texto poco menos de dos siglos después de su aparición, y su circulación y uso en escenarios rurales. A pesar de ser una obra decisiva, no es mucho lo que se sabe sobre la posesión y la aplicación del Ritual por sacerdotes: después de la posesión en el siglo XVII ${ }^{84}$, se ha podido encontrar solamente otra referencia dentro de las posesiones del cura vicario Juan Martínez de Legarza, clérigo de la doctrina de Carabayllo en la diócesis de Lima, en 1768. Dicho ejemplar fue tasado en 1 peso 4 reales, un valor incluso entonces no muy alto para un libro voluminoso ${ }^{85}$. En la biblioteca del cura Fernando y aparte de esta referencia a un material impreso relacionado al quechua, no se registraron otros títulos vinculados a lenguas indígenas. Si bien se encontraron otros materiales para la traducción, estos eran para el latín (Diccionario de Rubiños y el Arte Explicado). No obstante, el carácter predominantemente religioso de la colección del cura Fernando, los libros despertaron la codicia de otras personas de su entorno.

\section{Los libros perdidos del cura: sustracción y robo}

En unos pocos años, la biblioteca de don Fernando experimentó una fuerte reducción: de 157 libros a 61, una disminución a casi el 40\%. Mientras que la mayoría de los inventarios de libros ofrecen una imagen estática de una colección en un momento particular en el pasado, este caso excepcional -que cuenta con dos fuentes separadas por dos años- permite indagar en la deformación de la biblioteca. Como veremos, esta merma puede indicar dos aspectos relacionados entre sí. Primero, personas de la órbita de don Fernando sabían de la existencia de la biblioteca e inten-

81 La bibliografía basada en la obra de Pérez Bocanegra es vasta. Entre otros, destacan Mannheim, 1991; Harrison, 2002; Viola Casalongüe, 2010; Bendezú, 2014.

82 Mannheim, 2012: XXIV; Itier, 2012.

83 Sobre la historia de la publicación se sabe de las dificultades que padeció Juan Pérez Bocanegra. Había compuesto un primer manuscrito en 1610, el cual tuvo que corregir después del Rituale romanum en 1614. El permiso para imprimir lo consiguió recién en 1622, pero incluso así, el proceso demoró aún más y fue solo nueve años después que se imprimió. El mismo autor tuvo que desembolsar de su propio peculio para la publicación la suma considerable de 2,800 pesos para las 1,200 copias. Miembros de la orden dominica lo apoyaron en el proceso de publicación como cuando tuvo que volver a Andahuaylillas antes de que se acabó la impresión. Durston, 2007 : $155-156$.

84 En 1670 y en el arzobispado de Lima, el cura Bernardo Sandoval poseyó un ejemplar, tasado en dos pesos, Guibovich Pérez, 2010: 123.

85 Autos del cumplimiento del testamento del licenciado don Juan Martínez de Legarza. Lima, 18-VI-1778. Archivo Arzobispal de Lima [Perú], Testamento 169.14, f. 50. 
taron adueñarse de ella. Segundo, independiente del género y filiación étnica, tanto mujeres como varones de su círculo cercano fueron sospechosos de la substracción, quienes debieron tener un interés particular en ellos.

A pesar de su condición eclesiástica, don Fernando tuvo hijos naturales ${ }^{86}$. Una fue Polonia, que al parecer nació en Umachiri, era ladina y se casó con un hacendado español de la localidad ${ }^{87}$. Otro hijo carnal fue Luis Ramos Titu Atauchi, quien luego sería el segundo procurador general de naturales de la Audiencia de Cusco y uno de los primeros notarios en la etapa republicana, es decir, letrado y altamente versado en el derecho procesal ${ }^{88}$. Sabemos que él acompañó a su padre en sus últimas horas en su curato. Sin existir documentación que lo sustente, se podría considerar que Luis Ramos estuvo en la casa de su padre en otras ocasiones anteriores, donde pudo haber consultado los libros o, al menos, tener contacto con la cultura libresca. ¿Tuvieron los hijos acceso a su biblioteca, motivada por la educación brindada por su progenitor? No podemos afirmarlo o negarlo, sólo sugerir la idea que el proceso de alfabetización pudo ser incentivado por personajes que cultivaban significativamente el hábito de la lectura.

Las referencias sobre la biblioteca de Fernando Ramos datan de dos momentos, separados entre sí solamente de dos años: 1807 y 1809. A pesar de este corto tiempo, los datos disponibles permiten formular las siguientes ideas sobre la cultura libresca en los Andes. El primer dato valioso se refiere a la cantidad. En la memoria testamentaria de 1807 -que sería firmada por el cura indígena, pero cuya veracidad será discutida en las salas de la Audiencia de Cusco a lo largo de varios años- se detalla la existencia de 157 libros $^{89}$. La drástica reducción, producida dos años después, fue registrada por el subdelegado de Lampa, Juan Francisco Reyes, anotando alrededor de 60 títulos. En las diligencias emprendidas por la autoridad real se precisó que la gran parte de los bienes fueron saqueados por su entorno más cercano, compuesto por dos parejas íntimamente entrelazadas: los esposos Polonia y Andrés Cornejo; y Asencia Ramos con Buenaventura Cornejo. Los varones eran hermanos entre sí y las esposas lo mismo, además de ser las hijas de don Fernando. Adicionalmente, Buenaventura aseguraba haber sido nombrado albacea de Fernando en el dudoso

86 Aunque la temática de los hijos naturales de curas durante la época virreinal ha sido poco estudiada, se presenta como un campo fascinante. Se encuentran expedientes al respecto tanto en el Archivo Regional como en el Archivo Arzobispal de Cusco de reclamo de herencia por "hijos naturales" de curas. Junto a esta documentación se puede encontrar literatura legal (por ejemplo, Práctica de testamentos y modos de suceder por Juan de la Ripia) donde definen el porcentaje de herencia que pueden obtener los hijos de clérigos. A pesar de ello, los hijos naturales no fueron bien vistos en la sociedad. Por ese sentido, no llama la atención que en la testamentaria de Fernando Ramos no se precisó a Luis Ramos como hijo, sino vagamente como un familiar. En otros casos, se nombraron incluso herederos de colecciones, como lo deseó el presbítero Juan de Aragón en Cusco, poseedor de 33 libros, cuales se pasaron a tal universal heredero, un niño de ocho años, Mariano de Aragón, "nacido en mi casa a quien lo he criado como es constante con el amor de Padre solo p. ${ }^{\mathrm{r}}$ ser hijo de una criada". Testamento del presbítero don Juan de Aragón. Cusco, 14-I-1807. ARC, Escribano Pedro Joaquín de Gamarra, Prot. 78, Año 1807, f. 267. Sobre la situación problemática de los hijos de curas, los hijos ilegítimos, expósitos e hijos de padres desconocidos que aun así entraron como candidatos a órdenes menores y al servicio de la Iglesia, véase Lavallé, 1998: 108-110.

87 De los autos seguidos sobre la testamentaria del doctor don Fernando Ramos Tituatauchi. Cusco, 12-VI-1809. ARC, Real Audiencia, Leg. 66, Exp. 7, ff. 32r, 33v.

88 Zegarra Moretti, 2020b.

89 Autos seguidos por el procurador general de naturales don José Agustín Guamantupa, a nombre de don José Ramos Obando Tituatauchi, contra don Buenaventura Cornejo, vecino del pueblo de Umachiri. Cusco, 11-XII1810. ARC, Real Audiencia, Leg. 69, Exp. 25, f. 2v. 
escrito de última voluntad ${ }^{90}$. Se dispone de evidencias para sugerir que los impresos de Fernando Ramos no escaparon del expolio aludido. En un testimonio de Luis Ramos ante la autoridad de Lampa, advirtió que Andrés Cornejo "ha entregado a d" Silberio Mogrovejo unos Libros empastados nuebos, interceptándolos de la Libreria del citado $\mathrm{d}^{\mathrm{n}}$. Andres [Cornejo]" ${ }^{1}$. Andrés fue, a su vez, acusado de apoderarse de las llaves que custodiaban los bienes de don Fernando, entre los que se encontraban sus "libros y papeles" ${ }^{92}$. Buenaventura, hermano de Andrés, fue incriminado, en enero de 1810 por don Manuel Miranda, estanciero local, por ser quien "arrancó unos libros del estante y se [los] llevó"'93.

El caso se enredó aún más: unos meses después de la muerte del eclesiástico se hace la denuncia de otro hurto de libros ocurrido en Umachiri. El mencionado Andrés Cornejo, por medio de una carta dirigida a su hermano Buenaventura, fechada en dicho lugar el 30 de junio de 1809, denunció que sufrió un robo de ocho libros suyos de "artes liberales", por los cuales había pagado 60 pesos; un precio, por cierto, bastante alto para solamente ocho títulos. En la comunicación, que tiene por objeto pedir que su destinatario nombre un abogado para incoar una denuncia ante la Audiencia de Cusco, alude rápidamente a los títulos sustraídos. De ellos hemos podido identificar tres: Teatro crítico por Benito Jerónimo Feijoo, Ordinario de la Santa Misa por Fernando Amado Pouget, y Cristiano instruido en su ley por Pablo Señeri. Todos estos tuvieron gran difusión en la época, sin embargo, destaca la obra del monje benedictino Feijoo, egregio representante de la Ilustración católi$\mathrm{ca}^{94}$. La descripción de las otras obras substraídas es parca, aunque indican materias variadas: "Aritmética", "Geografía", "Ortografía", posiblemente "Repertorio", uno de Sigüenza ${ }^{95}$. Conformando solo una parte de un botín mayor que incluyó escrituras de tierras, alhajas y vestimenta, los libros perfilan cierta inclinación lectoral de su propietario.

Andrés Cornejo no dudó en inculpar a su mujer Polonia, quien igualmente era letrada ${ }^{96}$. Tras la muerte de don Fernando, ella dejó Umachiri y se refugió en la ciudad de Cusco. Sobre la fuga existen dos versiones. Según su marido, Polonia huyó porque abandonó al esposo. Este acusó a su mujer de ser adúltera con su propio primo, quien era, por cierto, fraile franciscano. La versión de la mujer, al contrario, contiene que escapó por maltrato y peligro de muerte. No se ha encontrado detalle del origen

90 De los autos seguidos sobre la testamentaria del doctor don Fernando Ramos Tituatauchi. Cusco, 12-VI-1809. ARC, Real Audiencia, Leg. 66, Exp. 7.

91 Autos ejecutivos seguidos por el defensor general contra la estancia de Totorani, casa y tierras en la parroquia de Santa Ana y demás bienes del doctor don Fernando Ramos Titoatauchi, cura de la doctrina de Humachiri. Cusco, 30-IX-1808. ARC, Cabildo, Leg. 76, Exp. 1889, f. 21v.

92 Autos ejecutivos seguidos por el defensor general contra la estancia de Totorani, casa y tierras en la parroquia de Santa Ana y demás bienes del doctor don Fernando Ramos Titoatauchi, cura de la doctrina de Humachiri. Cusco, 30-IX-1808. ARC, Cabildo, Leg. 76, Exp. 1889, f. 22r.

93 De los autos seguidos sobre la testamentaria del doctor don Fernando Ramos Tituatauchi. Cusco, 12-VI-1809. ARC, Real Audiencia, Leg. 66, Exp. 7, ff. 65r-67r.

94 Sobre el monje benedictino como fundador temprano de la Ilustración española, véase, por ejemplo, SánchezBlanco, 2002: 36-37.

95 De los autos seguidos sobre la testamentaria del doctor don Fernando Ramos Tituatauchi. Cusco, 12-VI-1809. ARC, Real Audiencia, Leg. 66, Exp. 7, f. 39v.

96 Polonia redactó y firmó, estando recluida en el beaterio de San Blas, en Cusco, un escrito a la audiencia. La autenticidad y veracidad de este escrito, en el que adapta su identidad presentándose como "india noble", fue confirmado por las instancias respectivas, De los autos seguidos sobre la testamentaria del doctor don Fernando Ramos Tituatauchi. Cusco, 12-VI-1809. ARC, Real Audiencia, Leg. 66, Exp. 7, ff. 32r-34v. 
de los libros desaparecidos, por lo que no sabemos si pertenecieron al padre de Polonia, lo que hubiera podido justificarse al ser ella una de las herederas nombradas en la supuesta memoria de su padre. Testimonia sí la existencia de más libros en Umachiri, ahora por el español Andrés. ¿Esta selectiva colección de "artes liberales" fue adquirida legalmente por Andrés o perteneció a los títulos de la colección del cura Fernando siendo traspasada en vida (ya sea por venta o donación) o fue parte del expolio que se comentó? Si tomamos como verdadera la última opción, podríamos resaltar que la posesión de libros debe contemplar, asimismo, el traspaso entre varios sujetos ligados al propietario reconocido: desde el principal poseedor - en este caso, don Fernando Ramos- a su entorno cercano compuesto por hijas y yernos.

Pero ¿cuál pudo ser el interés en estos libros? Esta respuesta puede responderse considerando a los libros como objetos de un interés particular o como parte de un botín mayor. En este último caso, puede verse como piezas menores de un conjunto de un mayor valor económico como joyas o escrituras de haciendas. En ese sentido, el libro podía revenderse y continuar con el itinerario. Por otro lado, el libro pudo tener otros valores simbólicos y sociales e, incluso, ser una herramienta de progreso. Hemos visto que Polonia escapó del entorno rural donde nació, el cual estuvo dominado por su párroco progenitor y estando ella sujeta a los intereses de este al ser desposada con un hacendado local, con quien se establecieron vínculos empresariales ${ }^{97}$. Fugar de Umachiri, alejarse de su esposo y migrar a Cusco para empezar una nueva vida con una identidad privilegiada supuso, además del apoyo de sus familiares residentes en la capital cusqueña y miembros de la nobleza, disponer de medios para insertarse en su nuevo escenario. Si la substracción fue cierta, quizá los libros le pudieron ser de alguna utilidad para Polonia en la antigua capital incaica. Después de ello, las huellas de los libros vuelven a desaparecer.

\section{Conclusiones}

A partir de un caso concreto y bien documentado, se ha demostrado la presencia de libros en el altiplano peruano. Podemos no solo asegurar su existencia en ese espacio indígena como lo refleja el inventario analizado, sino poder trazar el proceso de alfabetización y las opciones de acceso a los libros, además de su movimiento entre puntos de producción transatlántica, compra urbano-rural, almacenamiento en la casa y transmisión entre dueños legítimos y quienes se apropiaron del material. La biblioteca de don Fernando presenta una oportunidad de conocer al dueño, un lector indígena, con más detenimiento. Sin duda, don Fernando y su biblioteca escapan de la imagen que se dispone del grupo indígena letrado al no poseer material legal, sino, más bien, religioso y de carácter muy específico, lo cual coincidió con las labores pastorales en una zona sobre todo indígena y de habla quechua. Aparte del Ritual formulario, la colección representa el canon español típico de literatura religiosa de la época con muchos títulos en reimpresiones. Particularmente, su biblioteca demuestra el influjo de las obras del siglo XVII y especialmente la persistencia de autores jesuitas en los Andes, a pesar de su extinción cuarenta años antes del inventario de la biblioteca. Sin embargo, la falta de estudios sobre curas indígenas no permite afirmar si el personaje estudiado es un caso aislado o representativo de este grupo.

97 Zegarra Moretti, 2020a. 
Por último, hay que destacar que los libros no despertaron interés únicamente por su dueño, sino que la colección experimentó diferentes substracciones por el entorno personal del propietario. Esto indica, sin duda, el valor simbólico, social y económico que pudo tener el libro en ambientes rurales por diferentes sujetos sin distinción de sexo o etnicidad.

\section{Referencias bibliográficas}

Adorno, Rolena. "La 'Ciudad letrada' y los discursos coloniales". Hispámerica, vol. 16, n⿳ 48 (1987), 3-24.

Alaperrine-Bouyer, Monique. "La biblioteca del colegio de yngas nobles: San Borja del Cuzco". Histórica vol. 29, nº 2 (2005), 163-183.

Alaperrine-Bouyer, Monique. La educación de las elites indígenas en el Perú colonial. Lima: IFEA, 2007.

Amado Gonzales, Donato. El estandarte real y la mascapaycha: historia de una institución inca colonial. Lima: PUCP, 2017.

Argouse, Aude. "De libros y otras cosas: el legado del obispo De la Puebla González. Santiago de Chile, 1705". Relaciones, vol. 144 (2015), 13-53.

Ayrolo, Valentina: "El sermón como instrumento de intermediación cultural. Sermones del federalismo cordobés, 1815-1852”. Nuevo Mundo Mundo Nuevos (2009). Disponible en https://journals.openedition.org/nuevomundo/57521

Ballantyne, Tony. "What Difference Does Colonialism Make? Reassessing Print and Social Change in an Age of Global Imperialism". En Agent of Change: Print Culture Studies after Elizabeth L. Eisenstein, editado por Baron, Sabrina Alcorn - Lindquist, Eric N. Shelvin, Eleanor F. Amherst, MA: Univ. of Massachusetts Pr., 2007, 342-352.

Bendezú, Raúl. "El léxico de parentesco del quechua según Juan Pérez Bocanegra (Cuzco, siglo XVII)". Lexis, vol. 38, n 2 (2014), 429-456.

Burns, Kathryn. "Beatas, 'decencia' y poder: la formación de una elite indígena en el Cuzco colonial". En Incas e Indios Cristianos: elites indigenas e identidades cristianas en los Andes coloniales, editado por Decoster, Jean-Jacques. Cusco: IFEA, 2002.

- Into the Archive: Writing and Power in Colonial Peru. Durham, NC - London: Duke UP, 2010.

Cahill, David. "Curas and Social Conflict in the Doctrinas of Cuzco, 1780-1814". Journal of Latin American Studies, vol. 16, n 2 (1984), 241-276.

Charles, John. "Trained by Jesuits: Indigenous Letrados in Seventeenth-Century Peru". En Indigenous Intellectuals: Knowledge, Power, and Colonial Culture in Mexico an the Andes, editado por Ramos, Gabriela - Yannakakis, Yanna. Durham, NC - London: Duke UP, 2014, 60-78.

Chocano Mena, Magdalena. La fortaleza docta: elite letrada y dominación social en México colonial (siglos XVI-XVII). Barcelona: Bellaterra, 2000.

Coudart, Laurence - Cristina Gómez Álvarez. "Las bibliotecas particulares del siglo XVIII: una fuente para el historiador". Secuencia, vol. 56 (2003), 173-192.

Cummings, Brian. "The Book as Symbol". En The Oxford Companion to the Book. Vol. I, editado por Michael F. Suarez, SJ. - H.R. Woudhyusen. Oxford: OUP, 2010, 63-65.

Dougnac Rodríguez, Antonio. "Reforma y tradición en la biblioteca de un obispo ilustrado de Chile: el caso de Francisco José de Marán (1780-1807)". Revista Chilena de Historia del Derecho, vol. 16 (1990), 579-658. 
Dueñas, Alcira. Indians and Mestizos in the Lettered City: Reshaping Justice, Social Hierarchy, and Political Culture in Colonial Peru. Boulder, CO: UP of Colorado, 2010.

Durston, Alan. Pastoral Quechua: The History of Christian Translation in Colonial Peru, 1550-1650. Notre Dame, IN: Univ. of Notre Dame Pr., 2007.

— "Native-Language Literacy in Colonial Peru: The Question of Mundane Quechua Writing Revisited”. Hispanic American Historical Review, vol. 88, n 1 (2008), 41-70.

Escobari de Quejazu, Laura. "La educación en la época colonial: Lima, Cuzco y Charcas S. XVI-XVIII". Anuario de Estudios Bolivianos, Archivísticos y Bibliográficos, vol. 15 (2009), 155-182.

Estenssoro, Juan Carlos. "Descubriendo los poderes de la palabra: funciones de la prédica en la evangelización del Perú (siglos XVI-XVII)". En La venida del reino: religión, evangelización y cultura en América, siglos XVI-XX, editado por Ramos, Gabriela - Urbano, Enrique. Cusco: Centro de Estudios Regionales Andinos "Bartolomé de Las Casas", 1994, 75-101.

Ferlan, Claudio. "Comuniar la fe: la predicación de los primeros jesuitas entre Austria y Perú (siglo XVI)". En Normatividad e instituciones eclesiásticas en el virreinato del Perú, siglos XVI-XIX, editado por Danwerth, Otto - Albani, Benedetta - Duve, Thomas. Frankfurt a.M.: Max Planck Institute for European Legal History, 2019, 111-133.

García Baquero, Antonio. La Carrera de Indias: suma de la contratación y océano de negocios. Sevilla: Algaida, 1992.

Garrett, David T. "La iglesia y el poder social de la nobleza indígena cuzqueña, siglo XVIII". En Incas e indios cristianos: elites indigenas e identidades cristianas en los andes coloniales, editado por Decoster, Jean-Jacques. Cusco: IFEA, 2002, 295-311.

- Shadows of Empire: The Indian Nobility of Cusco, 1750-1825. Cambridge: CUP, 2005.

Gehbald, Agnes. "Popular Print Culture and the Book Market in Late Colonial Peru, 17631821 ”. Tesis doctoral, Universität zu Köln, 2020.

Glave, Luis Miguel. “La ilustración y el pueblo: el ‘loco’ Bernardino Tapia. Cambio y hegemonía cultural en los Andes al fin de la colonia. Azángaro, 1818”. Tiempos de América, vol. 12 (2005), 133-149.

González Sánchez, Carlos Alberto. "Los libros de los españoles en el virreinato del Perú (siglos XVI y XVII)". Revista de Indias, vol. 56 (1996), 7-47.

Guibovich Pérez, Pedro. "Lectura y difusión de la obra del Inca Garcilaso en el virreinato peruano (siglos XVII-XVIII): el caso de los Comentarios Reales". Revista Histórica, vol. 37 (1990a), 103-120.

— “Los libros del Curaca de Tacna”. Histórica, vol. 14, 1 (1990b), 69-84.

— "La educación en el Perú colonial: fuentes e historiografía". Histórica, vol. 17, n 2 (1993), 271-296.

— "Los libros de los doctrineros en el virreinato del Perú, siglos XVI-XVII". En Esplendores y miserias de la evangelización de América, editado por Oesterreicher, Wulf Schmidt-Riese, Roland. Berlin: De Gruyter, 2010, 95-132.

- Tradición y modernidad. La biblioteca del obispo Pedró José Chávez de la Rosa. Lima: PUCP-UP-IEP, 2014.

— "Indios y libros en el virreinato del Perú". En Sujetos coloniales: escritura, identidad y negociación en Hispanoamérica, siglos XVI-XVIII, editado por Cabanillas Cárdenas, Carlos F. New York, NY: IDEA, IGAS, 2017, 171-193.

Harrison, Regina. "Pérez Bocanegra's Ritual formulario: Khipu Knots and Confession”. En Narrative Threads, editado por Quilter, Jeffery - Urton, Gary. Austin, TX: Univ. of Texas Pr., 2002, 266-290. 
Inch, Marcela. "El mundo letrado de los lupaca: alfabetización y primeras letras a fines del siglo XVI e inicios del XVII". En Pleitos y riqueza: los caciques andinos en Potosí del siglo XVII, editado por Medinaceli, Ximena. Sucre: Ediciones del Archivo y Biblioteca Nacionales de Bolivia, 2010, 507-527.

Itier, César. "Juan Pérez Bocanegra y el Ritual formulario". En Juan Pérez Bocanegra. Ritual formulario, e institución de curas, para administrar a los naturales de este reino los santos Sacramentos del Bautismo, Confirmación, Eucaristía y Viático, Penitencia y Matrimonio, con advertencias muy necesarias, editado por Paredes Pando, Óscar - Valderrama Fernández, Ricardo - Rozas Álvarez, Washington. Cusco: Universidad Nacional San Antonio Abad del Cusco, 2012, XXIX-LXXII.

Lavallé, Bernard. "Los nuevos rasgos del bajo clero en el obispado de Arequipa a finales del siglo XVIII". Caravelle, vol. 70 (1998), 97-116.

— "Hacia un nuevo clero en los Andes a finales del siglo XVIII: la ordenación 'A título de lengua' en el Arzobispado de Lima”. Revista de Indias, vol. 71, 252 (2011), 391-414.

Macera, Pablo. "Noticias sobre la enseñanza elemental en el Perú durante el siglo XVIII". Revista histórica, vol. 29 (1966), 327-376.

— "Bibliotecas peruanas del siglo XVIII". En Trabajos de historia. Lima: Instituto Nacional de Cultura, 1977, 283-312.

Mannheim, Bruce. The Language of the Inka Since the European Invasion. Austin, TX: Univ. of Texas Pr., 1991.

— "Leer a Juan Pérez Bocanegra, su Ritual Formulario y Hanaq pachap kusikuynin". En Juan Pérez Bocanegra. Ritual formulario, e institución de curas, para administrar a los naturales de este reino los santos Sacramentos del Bautismo, Confirmación, Eucaristía y Viático, Penitencia y Matrimonio, con advertencias muy necesarias, editado por Paredes Pando, Óscar - Valderrama Fernández, Ricardo - Rozas Álvarez, Washington. Cusco: Universidad Nacional San Antonio Abad del Cusco, 2012, XXI-XXXVII.

Martínez de Sánchez, Ana María (dir.). Algunos sujetos y objetos de la oratoria sagrada en América colonial. Córdoba: Centro de Investigaciones y Estudios sobre Cultura y Sociedad, 2014.

Medina, José Toribio. La imprenta en Lima (1584-1824). Santiago de Chile: Impreso y grabado en casa del Autor, 1905.

Menegus, Margarita. "Las carreras académicas y eclesiásticas de algunos indígenas en el siglo XVIII”. En Ilustración en el mundo hispánico: preámbulo de las independencias, editado por Koprivitza Acuña, Milena - Ramos Medina, Manuel - Torales Pacheco, María Cristina. Tlaxcala: Gobierno del Estado de Tlaxcala, Universidad Iberoamericana, 2009, 277-289.

Menegus, Margarita - Aguirre, Rodolfo. Los indios, el sacerdocio y la Universidad en Nueva España, siglos XVI-XVIII. México: Universidad Nacional Autónoma de México, Plaza y Valdés, 2006.

Monsalve Zanatti, Martín. “Curacas pleitistas y curas abusivos: conflicto, prestigio y poder en los andes coloniales, siglo XVII". En Elites indígenas en los Andes: nobles, caciques y cabildantes bajo el yugo colonial, editado por Cahill, David - Tovías, Blanca. Quito: Ediciones Abya-Yala, 2003, 159-174.

Novoa, Mauricio. The Protectors of Indians in the Royal Audiencia of Lima: History, Careers and Legal Culture, 1575-1775. Leiden - Boston, MS: Brill, 2016.

O’Phelan Godoy, Scarlett. La gran rebelión en los Andes: de Túpac Amaru a Túpac Catari. Cusco: Centro de Estudios Regionales Andinos “Bartolomé de Las Casas”, 1995.

_ “Ascender al estado eclesiástico': la ordenación de indios en Lima a medianos del siglo XVIII”. En Incas e indios cristianos: elites indigenas e identidades cristianas en los andes coloniales, editado por Decoster, Jean-Jacques. Cusco: IFEA, 2002, 311-330. 
- Mestizos reales en el virreinato del Perú. Lima: Fondo Editorial del Congreso del Perú, 2013.

Palau y Dulcet, Antonio. Manual del librero hispano-americano: bibliografía general española e hispano-americana desde la invención de la imprenta hasta nuestros tiempos, con el valor comercial de los impresos descritos. Barcelona: Librería Palau, 1954-1955.

Puente Luna, José Carlos de la - Honores, Renzo. "Guardianes de la real justicia: alcaldes de indios, costumbre y justicia local en Huarochirí colonial. Histórica, vol. 40, nº 2 (2016), $11-47$.

Rama, Ángel. La ciudad letrada: prólogo de Carlos Monsilváis. Santiago: Tajamar, 2004.

Ramírez, Susan Elizabeth. "To Serve God and King: The Origins of Public Schools for Native Children in Eighteenth-Century Northern Peru". Colonial Latin American Review, vol. 17, 1 (2008), 73-99.

Ramos, Gabriela. "Indigenous Intellectuals in Andean Colonial Cities". En Indigenous Intellectuals: Knowledge, Power, and Colonial Culture in Mexico an the Andes, editado por Ramos, Gabriela - Yannakakis, Yanna. Durham, NC - London: Duke UP, 2014, 21-38.

Ramos, Gabriela - Yannakakis, Yanna. "Introduction". En Indigenous Intellectuals: Knowledge, Power, and Colonial Culture in Mexico an the Andes, editado por Ramos, Gabriela - Yannakakis, Yanna. Durham, NC / London: Duke UP, 2014, 1-20.

Rappaport, Joanne - Cummins, Thomas B. F. Beyond the Lettered City: Indigenous Literacies in the Andes. Durham, NC: Duke UP, 2012.

Rial, Benito. "Sixteenth-Century Private Book Inventories and Some Problems Related to their Analysis". Library \& Information History, vol. 26, n 1 (2010), 70-82.

Rosas Lauro, Claudia. "Madre sólo hay una. Ilustración, maternidad y medicina en el Perú del siglo XVIII". Anuario de Estudios Americanos, vol. 61, n 1 (2004), 103-138.

Sánchez-Blanco, Francisco. El absolutismo y las luces en el reinado de Carlos III. Madrid: Marcial Pons, 2002.

Soule, Emily Berquist. The Bishop's Utopia: Envisioning Improvement in Colonial Peru. Philadelphia, PA: Univ. of Philadelphia Pr., 2014.

Temple, Ella Dunbar. "Un linaje incaico durante la dominación española: los Sahuaraura”. Revista Histórica. Lima, vol. 18 (1949), 45-77.

Thibaud, Clément. La Academia Carolina y la independenciade América. Sucre: Editorial Charcas, 2010.

Torre Revello, José Miguel. El libro, la imprenta y el periodismo en América durante la dominación española. Buenos Aires: Jacobo Peuser, 1940.

Valcárcel, Daniel. Historia de la educación colonial. Lima: Universo S.A., 1968.

Vargas Ugarte, Rubén. "La instrucción primaria en el Perú virreinal”. Fénix, vol. 22 (1972), 162-167.

Villanueva Urteaga, Horacio. "El testamento y la biblioteca de Ignacio de Castro". Revista del Archivo General de la Nación, Lima, n 2 (1974), 155-165.

Viola Casalongüe, Gabriel. "Nuevos datos sobre la biografía e itinerario pastoral de Juan Pérez Bocanegra". Allpanchis, $\mathrm{n}^{\circ} 75$ (2010), 143-185.

Walker, Charles F. La rebelión de Túpac Amaru. Lima: Instituto de Estudios Peruanos, 2015.

Walsby, Malcolm. "Book Lists and Their Meaning". En Documenting the Early Modern Book World: Inventories and Catalogues in Manuscript and Print, editado por Malcolm Walsby - Natasha Constantinidou, Leiden: Brill, 2013, 1-26.

Zegarra Moretti, Carlos. "El retrato de un cura indígena del Cusco tardío virreinal: vida y relaciones de don Fernando Ramos Titu Atauchi”. Boletín Americanista, n 80 (2020a), 211-230. 
— "Los procuradores de naturales de las audiencias de Lima y Cusco: la etapa indígena y su impacto en la defensa legal a fines del periodo virreinal". Nuevo Mundo Mundo Nuevos (2020b). Disponible en https://journals.openedition.org/nuevomundo/79467

\section{Anexo documental}

El inventario, que a continuación se reproduce, pertenece al expediente resguardado en el Archivo Regional del Cusco (ARC, Cabildo, Legajo 76, Expediente 1889, ff. 13r-14r). Los datos son organizados por cada título y en dos columnas, en donde se consta la transcripción paleografía en una y en la otra la identificación bibliográfica cuando ha sido establecida, con la primera edición en paréntesis, o existe la posibilidad.

Tabla 1. Inventario de los libros de don Fernando Ramos Titu Atauchi.

\begin{tabular}{|c|c|c|}
\hline$\#$ & Transcripción & Identificación bibliográfica \\
\hline 1 & $\begin{array}{l}\text { Yt. Luz de la fee y la verdad un } \\
\text { tomo. }\end{array}$ & No identificado. \\
\hline 2 & $\begin{array}{l}\text { Yt. Despertador cristiano dos tomos, } \\
\text { mas uno. }\end{array}$ & $\begin{array}{l}\text { Despertador cristiano de sermones doctrinales sobre } \\
\text { particulares assuntos (1693), por Joseph de Barzia y } \\
\text { Zambrana. }\end{array}$ \\
\hline 3 & Yt Luz de verds católicas un tomo. & $\begin{array}{l}\text { Luz de verdades cathólicas y explicaciones de la } \\
\text { doctrina christiana, que según la costumbre de la Casa } \\
\text { professa de la Compañia de Jesús de México, todos los } \\
\text { jueves del año se platica en su Iglesia (1691-1695, } 3 \\
\text { tomos), por Juan Martínez de la Parra, jesuita. }\end{array}$ \\
\hline 4 & $\begin{array}{l}\text { Yt. Perpect. Confesor sin principio } \\
\text { un } \mathrm{t}^{\circ} \text {. }\end{array}$ & $\begin{array}{l}\text { Posiblemente: Perfeto confesor y cura de almas } \\
\text { (1641), por Iván Machado de Chávez. }\end{array}$ \\
\hline 5 & Yt. Tesauro Politico moral un $t^{\circ}$. & No identificado. \\
\hline 6 & Yt. Enemigma [sic] numerico un $\mathrm{t}^{\circ}$. & $\begin{array}{l}\text { Enigma numerico predicable (1678), por Iván de } \\
\text { Mora, franciscano. }\end{array}$ \\
\hline 7 & Yt. Concilio Tridentino un $t^{\circ}$. & $\begin{array}{l}\text { El sacrosanto y ecuménico concilio de Trento (1564), } \\
\text { traducido por Ignacio López de Ayala. }\end{array}$ \\
\hline 8 & $\begin{array}{l}\text { Yt. Parte de la Yntroducs }{ }^{\mathrm{n}} \text {. del } \\
\text { Simbulo [sic] de la fé } 1 \mathrm{t}^{\circ} \text {. }\end{array}$ & $\begin{array}{l}\text { Primera parte de la introducción del simbolo de la fe } \\
\text { (1583), por Luis de Granada, franciscano. }\end{array}$ \\
\hline 9 & Yt. Suma de la Teologia moral $4 \mathrm{~T}$. & $\begin{array}{l}\text { Suma de la teologia moral y canonica (1620-1623), } \\
\text { por Enrique de Villalobos, franciscano. }\end{array}$ \\
\hline 10 & Yt. Ave Maria Quaresma cont ${ }^{\mathrm{a}} .3 \mathrm{t}$. & $\begin{array}{l}\text { Ave Maria. Quaresma continua, oraciones evangelicas } \\
\text { para todos los dias (1697), por Manuel Guerra y } \\
\text { Rivera, trinitario calzado. }\end{array}$ \\
\hline
\end{tabular}




\begin{tabular}{|c|c|c|}
\hline \# & Transcripción & Identificación bibliográfica \\
\hline 11 & 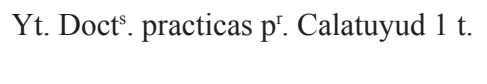 & $\begin{array}{l}\text { Doctrinas prácticas que solía explicar en sus misiones } \\
\text { (1737), por Pedro de Calatayud, jesuita. }\end{array}$ \\
\hline 12 & Yt. El Gov'. cristiano 1t. & $\begin{array}{l}\text { El gobernador christiano, deducido de la vida de } \\
\text { Moysen, principe del pueblo de Dios (1612), por Juan } \\
\text { Márquez, agustino. }\end{array}$ \\
\hline 13 & Yt. Bonet Teologia moral 1. t. & $\begin{array}{l}\text { Posiblemente: Suma de la teología moral y canónica, } \\
\text { primera parte, por el P. Fr. Enrique de Villalobos } \\
\text { [franciscano] [...] a costa de Juan Antonio Bonet, } \\
\text { mercader de libros (1668). }\end{array}$ \\
\hline 14 & $\begin{array}{l}\text { Yt. Año Cristiano 16, T. mas uno, } \\
\text { mas otro. }\end{array}$ & $\begin{array}{l}\text { Año christiano, o, Exercicios devotos para todos los } \\
\text { días del año, contiene la explicación del mysterio o } \\
\text { la vida del santo correspondiente a cada día, algunas } \\
\text { reflexiones sobre la epistola, una meditación después } \\
\text { del evangelio de la misa, y algunos exercicios prácticos } \\
\text { de devoción o propósitos adaptables a todo género de } \\
\text { personas (desde 1753), por Jean Croiset, jesuita. }\end{array}$ \\
\hline 15 & Yt. Sermones Panegiricos 6 t. & $\begin{array}{l}\text { Sermones panegiricos (1793, } 6 \text { tomos), por Joseph } \\
\text { Francisco de Isla, jesuita. }\end{array}$ \\
\hline 16 & Yt. Monarqa . Hebrea 2. t. & $\begin{array}{l}\text { Monarquía hebrea (1702), por Vicente Bacallar y } \\
\text { Sanna. }\end{array}$ \\
\hline 17 & $\begin{array}{l}\text { Yt. Suma Moral del P. Bern }{ }^{\text {do }} \\
\text { Pacheco 2. t. }\end{array}$ & $\begin{array}{l}\text { Suma moral escrita en breve compendio }(1751,2 \\
\text { tomos) por Bernardo Pacheco, cisterciense. }\end{array}$ \\
\hline 18 & $\begin{array}{l}\text { Yt. Los Reyes nuebos de Toledo } 1 . \\
\text { T. }\end{array}$ & $\begin{array}{l}\text { Historia de los reyes nuevos de Toledo }(1667,4 \\
\text { tomos), por Cristóbal Lozano. }\end{array}$ \\
\hline 19 & Yt. Cliqued Flor del moral 1. t. & $\begin{array}{l}\text { La flor del moral, esto es, lo mas florido, y selecto } \\
\text { que se halla en el jardín ameno, y dilatado campo de } \\
\text { la teología moral (1733), por Josef Faustino Cliquet, } \\
\text { agustino. }\end{array}$ \\
\hline 20 & $\begin{array}{l}\text { Yt. Serms. del P. Larruc, } 3 \text { t. uno } \\
\text { mas. }\end{array}$ & $\begin{array}{l}\text { Posiblemente: Sermones [...], por Jerónimo Bautista de } \\
\text { Lanuza (1533-1624), dominicano. }\end{array}$ \\
\hline 21 & Yt. Teologa . moral del D. Cebas 1.t. & No identificado. \\
\hline 22 & Yt. El Cura instruido 1.t. & $\begin{array}{l}\text { El cura instruido, obra, en que se muestra a qualquier } \\
\text { cura nuevo la obligacion que le incumbe, y el cuidado que } \\
\text { ha de poner en cumplirla (1695), por Pablo Señeri, jesuita. }\end{array}$ \\
\hline 23 & Yt. Formulario de Curas 1.t. & $\begin{array}{l}\text { Ritual formulario e institución de curas, para administrar } \\
\text { a los naturales de este reyno, los santos sacramentos del } \\
\text { baptismo, confirmacion, Eucaristia, y Viatico, Penitencia, } \\
\text { Extremauncion, y Matrimonio, con advertencias muy } \\
\text { necesarias (1631), por Juan Pérez Bocanegra. }\end{array}$ \\
\hline 24 & Yt. Triunfos de la Grac ${ }^{a}$. 1t. & $\begin{array}{l}\text { Posiblemente: Triunfos de la gracia y gloria de los } \\
\text { santos (1679), por Francisco Alberto de San Cirilo, } \\
\text { carmelita. }\end{array}$ \\
\hline
\end{tabular}




\begin{tabular}{|c|c|c|}
\hline \# & Transcripción & Identificación bibliográfica \\
\hline 25 & Yt. Hechos Eroicos de $\mathrm{S}^{\mathrm{n}}$. $\operatorname{Sim}^{\mathrm{n}}$ 1. t. & $\begin{array}{l}\text { Posiblemente: Exclamacion a los heroicos hechos del } \\
\text { eremita del ayre, ave celeste, maravilloso príncipe de } \\
\text { los Stylitas San Simeon (1680), por Andrés Antonio } \\
\text { Sánchez de Villamayor. }\end{array}$ \\
\hline 26 & $\begin{array}{l}\text { Yt. El Olimpo del Sabio maximas } \\
\text { 1. t. }\end{array}$ & $\begin{array}{l}\text { Posiblemente: El olimpo del sabio instruido de } \\
\text { la naturaleza, en diez y ocho máximas politicas y } \\
\text { morales, ilustradas con todo genero de erudición, } \\
\text { sacra y humana (1691), por Francisco Garau, jesuita. }\end{array}$ \\
\hline 27 & Yt. Curia Eclesiastica 1.t. & $\begin{array}{l}\text { Curia eclesiástica para secretarios de prelados, } \\
\text { notarios apostólicos, y ordinarios, latinos, y de visita, } \\
\text { con muchas y varias cosas, utiles y curiosas (1615), } \\
\text { por Francisco Ortiz de Salcedo. }\end{array}$ \\
\hline 28 & Yt. La Corte Santa 1t. mas otro. & $\begin{array}{l}\text { La corte santa, escrita en francés, (1670), por Nicolás } \\
\text { Causino, jesuita. }\end{array}$ \\
\hline 29 & Yt. El Sabio de la Natza $1 \mathrm{t}$. & $\begin{array}{l}\text { El sabio instruido }[\ldots] \text {, por Francisco Garau, jesuita } \\
\text { (compara con \# 26). }\end{array}$ \\
\hline 30 & Yt. David Arrepentido 1.t. & $\begin{array}{l}\text { El rey penitente David arrepentido. Historia sagrada, } \\
\text { autorizada con lugares de escritura, morales, y } \\
\text { exemplos (1656), por Cristóbal Lozano. }\end{array}$ \\
\hline 31 & $\begin{array}{l}\text { Yt. El hijo de David perseguido 1t } \\
\text { otro mas. }\end{array}$ & $\begin{array}{l}\text { El grande hijo de David más perseguido, Jesu-Cristo, } \\
\text { señor nuestro. Historia sagrada, parafraseada con } \\
\text { oraciones panegyricas, glossas dulces, vidas, historias } \\
\text { de santos (1663-1673), por Cristóbal Lozano. }\end{array}$ \\
\hline 32 & Yt. El Savio instruido 1t. & $\begin{array}{l}\text { El sabio instruido }[\ldots] \text {, por Francisco Garau, jesuita } \\
\text { (compara con \# 26). }\end{array}$ \\
\hline 33 & Yr. Sermon's del P. Ynterian 1t. & $\begin{array}{l}\text { Posiblemente: Sermones varios, predicables á diversos } \\
\text { assumptos (1703), por Juan Ynterian de Ayala, } \\
\text { mercedario calzado. }\end{array}$ \\
\hline 34 & $\begin{array}{l}\text { Yt. Coment }{ }^{\circ} \text {. de la Bula del Papa } \\
\text { desimo quar }{ }^{\text {to }} \text { 1.t. }\end{array}$ & No identificado. \\
\hline 35 & Yt. Sermones del P. Aguilar 1t. & $\begin{array}{l}\text { Sermones varios, predicados en la ciudad de Lima, } \\
\text { corte de los reinos del Perú (1704), por Joseph de } \\
\text { Aguilar, jesuita. }\end{array}$ \\
\hline 36 & Yt Serm ${ }^{\text {s. del P. San Andres 1.t. }}$ & $\begin{array}{l}\text { Posiblemente: Sermones varios, y novena de } S . \\
\text { Cayetano (1741) por José de San Andrés, mercedario. }\end{array}$ \\
\hline 37 & Yt. Tesauro 1.t. & No identificado. \\
\hline 38 & Yt. Ymagen de la Vida Crist ${ }^{\text {na }}$. 1.t. & $\begin{array}{l}\text { Posiblemente: Imagen de la vida cristiana (1593), por } \\
\text { Heitor Pinto, jerónimo. }\end{array}$ \\
\hline 39 & Yt. dos Libs. sin principio ni fin. & No identificable. \\
\hline 40 & Yt. Teologia Viva 1. t. & Opera omnia (1708), por Domenico Viva, jesuita. \\
\hline
\end{tabular}




\begin{tabular}{|c|c|c|}
\hline \# & Transcripción & Identificación bibliográfica \\
\hline 41 & $\begin{array}{l}\text { Yt. Un __ [¿manotreto?] mano } \\
\text { escrito. }\end{array}$ & No identificable. \\
\hline 42 & $\begin{array}{l}\text { Yt. Dicsionario de Rubiños 2.t en } \\
\text { pat }^{\mathrm{s}} \text { de a folio. }\end{array}$ & $\begin{array}{l}\text { Dictionarium revidium, sive, Novissimé emendatum, } \\
\text { auctum, locupletatum, \& in meliorem formam } \\
\text { restitutum }(1754,2 \text { tomos), por Elio Alonso de Nebrija } \\
\text { / Ildefonsum Lopez de Rubiños. }\end{array}$ \\
\hline 43 & $\begin{array}{l}\text { Yt. Origen Estado act }{ }^{1} \text {. de la } \\
\text { Literatura } 2 \text { tos. otro. }\end{array}$ & $\begin{array}{l}\text { Origen, progresos y estado actual de toda literatura } \\
\text { (1784), por abate Juan Andrés, jesuita. }\end{array}$ \\
\hline 44 & Yt Serms del P. Elias 2. $t^{\mathrm{s}}$ en pats. & $\begin{array}{l}\text { Posiblemente: Oracion panegirica al Excelso, } \\
\text { celestial, y Diuino Patriarca S. Ioseph (1680), por } \\
\text { Andres Elias Caperó. }\end{array}$ \\
\hline 45 & Yt. Consilio Trento $1 \mathrm{t}$. & $\begin{array}{l}\text { El sacrosanto y ecuménico concilio de Trento (1564), } \\
\text { traducido por Ignacio López de Ayala (compara con \# 7). }\end{array}$ \\
\hline 46 & Yt. Exerc ${ }^{\mathrm{s}}$. del Cristiano $1 \mathrm{t}$. & No identificado. \\
\hline 47 & Yt. Bonet 1. t. otro mas. & No identificado. \\
\hline 48 & Yt. Semanario Erudito 1. t. & $\begin{array}{l}\text { Posiblemente: Semanario erudito, que comprehende } \\
\text { varias obras inéditas, críticas, morales, instructivas, } \\
\text { politicas, históricas, satíricas, y jococas, de nuestros } \\
\text { mejores autores antiguos, y modernos (1787-1791), } \\
\text { por Antonio Valladares de Sotomayor. }\end{array}$ \\
\hline 49 & Yt. Arte Explicado $1 \mathrm{t}$. & No identificado. \\
\hline 50 & Yt. Obras de Virgilio $1 \mathrm{t}$. & Las obras $[\ldots]$, por Publio Virgilio Marón. \\
\hline 51 & Yt Gaspar Guanin 1.t. & Gaspard Juénin (1650-1713). \\
\hline 52 & Yt. Primicia Panegiricas 1.t. & $\begin{array}{l}\text { Primicias panegyricas y morales en quince sermones, } \\
\text { cinco eucharisticos, cinco vespertinos historicos y } \\
\text { otros cinco euangelicos }[\ldots] \text { (... (1724), por Geronimo } \\
\text { Therrero, franciscano. }\end{array}$ \\
\hline 53 & Yt. Declamaciones Sacras 1. t. & $\begin{array}{l}\text { Declamaciones sacras, politicas y morales sobre los } \\
\text { evangelios todos de la Quaresma, con los assuntos } \\
\text { ocurrentes: de limosna, S. Mathias, S. Thomas, } \\
\text { Encarnacion, Dolores, Soledad, Patrocinio de la } \\
\text { Virgen Santisima, y el Mandato (1675), por Francisco } \\
\text { Garau, jesuita. }\end{array}$ \\
\hline 54 & Yt. Pablo Fidel 1. t. & $\begin{array}{l}\text { Posiblemente: Panegyrica oracion eloquente a los } \\
\text { desagravios del SSmo Sacramento [...] el dia } 17 \text { de } \\
\text { agosto de este año de 1739, por Fr. Pablo Fidel de } \\
\text { Burgos, capuchino. }\end{array}$ \\
\hline 55 & Yt. Biera 1. t. & Posiblemente: Antonio de Vieira (1608-1697), jesuita. \\
\hline 56 & Yt. Semones de Moreno 1. t. & $\begin{array}{l}\text { Sermones de los domingos, y principales ferias de la } \\
\text { Quaresma (1675), por Fray Pedro Moreno, carmelita. }\end{array}$ \\
\hline
\end{tabular}




\begin{tabular}{|c|l|l|}
\hline$\#$ & \multicolumn{1}{|c|}{ Transcripción } & \multicolumn{1}{c|}{ Identificación bibliográfica } \\
\hline 57 & Yt. Cosilio [sic] Trento 1. t. & No identificado (compara con \# 7). \\
\hline 58 & Yt. Un oficio Suelto Beletmitico. & No identificado. \\
\hline 59 & $\begin{array}{l}\text { Yt. Un juego de Brebiarios en 4. } \mathrm{t}^{\text {s. }} \\
\text { de a f. }\end{array}$ & No identificable. \\
\hline 60 & Yt. Otro juego de a octavo en $4 \mathrm{t}^{\mathrm{s}}$. & No identificable. \\
\hline 61 & $\begin{array}{l}\text { Yt. Un juego de Brebiarios pasados } \\
\text { de a quatro. }\end{array}$ & No identificable. \\
\hline
\end{tabular}


